\title{
Comparison of box-air-mass-factors and radiances for Multiple-Axis Differential Optical Absorption Spectroscopy (MAX-DOAS) geometries calculated from different UV/visible radiative transfer models
}

\author{
T. Wagner ${ }^{1,2}$, J. P. Burrows ${ }^{3}$, T. Deutschmann ${ }^{1}$, B. Dix ${ }^{1}$, C. von Friedeburg ${ }^{4}$, U. Frieß ${ }^{1}$, F. Hendrick ${ }^{5}$, K.-P. Heue ${ }^{1}$,

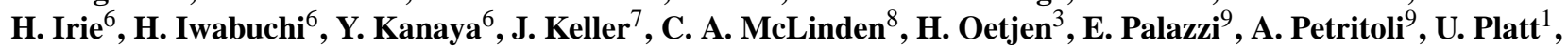 \\ O. Postylyakov $^{10}$, J. Pukite ${ }^{2}$, A. Richter ${ }^{3}$, M. van Roozendael ${ }^{5}$, A. Rozanov ${ }^{3}$, V. Rozanov ${ }^{3}$, R. Sinreich ${ }^{1}$, S. Sanghavi ${ }^{1}$, \\ and F. Wittrock ${ }^{3}$ \\ ${ }^{1}$ Institut für Umweltphysik, University of Heidelberg, Heidelberg, Germany \\ ${ }^{2}$ Max-Planck-Institute for Chemistry, Mainz, Germany \\ ${ }^{3}$ Institut für Umweltphysik, University of Bremen, Bremen, Germany \\ ${ }^{4}$ Wiley-VCH, Berlin, Germany \\ ${ }^{5}$ Institut d'Aéronomie Spatiale de Belgique, Brussels, Belgium \\ ${ }^{6}$ Frontier Research Center for Global Change, Japan Agency for Marine Earth Science and Technology, Yokohama, Japan \\ ${ }^{7}$ Paul Scherrer Institute, Villigen, Switzerland \\ ${ }^{8}$ Environment Canada, Toronto, Canada \\ ${ }^{9}$ Institute of Atmospheric Science and Climate, Bologna, Italy \\ ${ }^{10}$ Obukhov Institute of Atmospheric Physics, Moscow, Russia
}

Received: 18 August 2006 - Published in Atmos. Chem. Phys. Discuss.: 6 October 2006

Revised: 10 January 2007 - Accepted: 27 March 2007 - Published: 13 April 2007

\begin{abstract}
The results of a comparison exercise of radiative transfer models (RTM) of various international research groups for Multiple AXis Differential Optical Absorption Spectroscopy (MAX-DOAS) viewing geometry are presented. Besides the assessment of the agreement between the different models, a second focus of the comparison was the systematic investigation of the sensitivity of the MAX-DOAS technique under various viewing geometries and aerosol conditions. In contrast to previous comparison exercises, box-air-mass-factors (box-AMFs) for different atmospheric height layers were modelled, which describe the sensitivity of the measurements as a function of altitude. In addition, radiances were calculated allowing the identification of potential errors, which might be overlooked if only AMFs are compared. Accurate modelling of radiances is also a prerequisite for the correct interpretation of satellite observations, for which the received radiance can strongly vary across the large ground pixels, and might be also important for the retrieval of aerosol properties as a future application
\end{abstract}

Correspondence to: T. Wagner

(thomas.wagner@iup.uni-heidelberg.de) of MAX-DOAS. The comparison exercises included different wavelengths and atmospheric scenarios (with and without aerosols). The strong and systematic influence of aerosol scattering indicates that from MAX-DOAS observations also information on atmospheric aerosols can be retrieved. During the various iterations of the exercises, the results from all models showed a substantial convergence, and the final data sets agreed for most cases within about 5\%. Larger deviations were found for cases with low atmospheric optical depth, for which the photon path lengths along the line of sight of the instrument can become very large. The differences occurred between models including full spherical geometry and those using only plane parallel approximation indicating that the correct treatment of the Earth's sphericity becomes indispensable. The modelled box-AMFs constitute an universal data base for the calculation of arbitrary (total) AMFs by simple convolution with a given trace gas concentration profile. Together with the modelled radiances and the specified settings for the various exercises, they can serve as test cases for future RTM developments. 


\section{Introduction}

In June 2005, a workshop on radiative transfer modelling (RTM, we will use this abbreviation also for the term "radiative transfer model") for the UV and visible spectral range was held at University of Heidelberg, Germany (http://satellite.iup.uni-heidelberg.de/index.php/RTM_ Workshop). The aim of this workshop was to conduct a comparison of nine state of the art RTMs from various international research groups (see Sect. 2). These models use different approaches to solve the atmospheric radiative transfer equations; they also treat the spatial discretisation of the atmosphere and the Earth's sphericity in different ways or operate in plane parallel geometry (see Sect. 2). In the UV and visible spectral range, thermal emission can be neglected, and as relevant processes remain only absorption by molecules, aerosols and the Earth's surface as well as scattering (or reflection) on molecules, aerosols and the ground. Most of the participating RTMs were developed for the simulation of remote sensing observations from various platforms (e.g. ground, aircraft, balloon, satellite), which is a fundamental prerequisite for the correct interpretation of these observations. In addition, these RTMs can also be applied to investigate the energy deposition of the solar radiation in the Earth's atmosphere, which is especially interesting for cloudy conditions. Current state of the art RTMs simulate the Earth's sphericity, refraction and multiple scattering processes. Some models are capable of modelling polarisation and three-dimensional scenes. The latter is in particular important for the correct interpretation of satellite observations of atmospheric trace gases, because of their large ground pixels (the pixels sizes of current instruments range from about $15 \times 15 \mathrm{~km}^{2}$ to $300 \times 40 \mathrm{~km}^{2}$ (European Space Agency (ESA), 1995; Burrows et al., 1999; Bovensmann et al., 1999; Levelt and Noordhoek, 2002; EUMETSAT, 2005).

This comparison exercise has two main foci: first to quantify the agreement between the different models and give recommendations for future improvements and second to investigate the sensitivity of the MAX-DOAS technique for selected atmospheric scenarios and viewing geometries with specific focus on the influence of aerosols.

\subsection{Modelled quantities used for the comparison exercise}

As primary output, RTMs yield the radiance obtained by a detector (with a specified position, viewing direction and field of view) for a defined atmospheric scenario. For the interpretation of remote sensing measurements, however, the most important output is a measure for their sensitivity to atmospheric trace gases. Usually the sensitivity is expressed as so called Air Mass Factor (AMF) (Noxon et al., 1979; Solomon et al., 1987; Perliski and Solomon, 1993), which is defined as the ratio of the measured slant column density (SCD) and the vertical column density (VCD, the vertically integrated concentration):

$\mathrm{AMF}=\mathrm{SCD} / \mathrm{VCD}$

The SCD for a specific trace gas is derived from the DOAS analysis. For the observation of direct sun light, the SCD represents the trace gas concentration along the light path. For the observation of scattered sun light, however, many light paths contribute to the measured spectrum. Only for weak atmospheric absorbers, the SCD can be referred to the intensity weighted average of all light paths. Besides the observation geometry and the atmospheric properties, the AMF depends in particular on the spatial distribution of the trace gas of interest. For many applications, it is sufficient to know the relative vertical concentration profile.

Besides the specific focus on the MAX-DOAS observation geometry, this comparison exercise differs from previous exercises (Sarkissian et al., 1995; Potylyakov et al., 2001; Loughman et al., 2004; Hendrick et al., 2006) also in further aspects. First, in addition to the calculation of AMFs, radiances were also simulated and compared. The comparison of radiances is a very sensitive tool to test the correct performance of the RTMs, because it allows the identification of errors, which might not be detectable if only AMFs were compared (in the AMF-calculation potential errors of the modelled radiances typically cancel each other). In addition, the correct calculation of radiances is of great importance for the interpretation of satellite observations, for which the brightness within an observed ground pixel can vary strongly, especially for partly clouded scenes (Wagner et al., 2005). Moreover, modelled radiances will also be important for the retrieval of aerosol properties as a future application of MAX-DOAS (Wagner et al., 2004; Friess et al., 2006). For this comparison exercise, all modelled radiances are expressed as normalised radiance with respect to the solar irradiance:

$R_{\text {normalised }}=\frac{R}{I}$

Here $R$ and $I$ denote the modelled radiance and solar irradiance, respectively. The use of normalised radiances makes the comparison independent on the absolute values of the solar irradiance.

Another new aspect of this comparison exercise is that instead of AMFs for specific trace gas profiles, so called boxAMFs were calculated. Such Box-AMFs characterise the ratio of the partial SCD to the partial VCD of an atmospheric layer with an assumed constant trace gas concentration. It is interesting to note here, that for optically thin absorbers (optical depth $\ll 1)$, the box-AMFs are identical to the so called weighting functions (Rodgers, 1976, 2000). For these cases, they can also be approximated by the intensity weighted geometrical path length extension with respect to the vertical thickness of the selected layer, averaged over all contributing light paths. In this comparison exercise, only box-AMFs for optically thin absorbers were calculated. 
The great advantage of calculating box-AMFs is that they can serve as an universal data base to calculate appropriate (total) AMFs for arbitrary species with different height profiles. Total AMFs can be easily calculated from the box$\mathrm{AMFs}\left(\mathrm{AMF}_{i}\right)$ and the respective trace gas profile as the sum of the box-AMFs over the whole atmosphere weighted by the respective partial trace gas VCD:

$$
\mathrm{AMF}=\frac{\sum_{0}^{\mathrm{TOA}} \mathrm{AMF}_{i} \cdot \mathrm{VCD}_{i}}{\sum_{0}^{\mathrm{TOA}} \mathrm{VCD}_{i}}
$$

Here $\mathrm{AMF}_{i}$ and $\mathrm{VCD}_{i}$ refer to the box-AMF and the partial VCD for layer $\mathrm{i}$; within the layer the trace gas concentration is assumed to be constant. The sum is carried out over all layers $\mathrm{i}$ (from the surface to the top of the atmosphere, TOA). The vertical discretisation chosen for the calculation of the box-AMFs within these exercises is shown in Table 1.

\subsection{MAX-DOAS observations}

This comparison exercise focuses on the simulation of the recently developed Multiple AXis Differential Optical Absorption Spectroscopy (MAX-DOAS) technique (Hönninger and Platt, 2002; Leser et al., 2003; Bobrowski et al., 2003; van Roozendael et al., 2003; Hönninger et al., 2004; Wagner et al., 2004; Wittrock et al., 2004; Von Friedeburg et al., 2005; Heckel et al., 2005; Oetjen et al., 2006; Sinreich et al., 2005; Frieß et al., 2006; Frins et al., 2006). In contrast to the well established ground based observations of zenithscattered sun light (Noxon et al., 1979; Solomon et al., 1987), MAX-DOAS observations are directed into the illuminated atmosphere under various elevation angles. Since for a slant viewing geometry, the absorption paths through (and accordingly the AMFs for) the lower atmosphere can become rather large, MAX-DOAS observations are especially sensitive to tropospheric trace gases. From the combination of observations at several elevation angles (and several wavelengths), also information on the vertical trace gas profile can be obtained (see e.g. Hönninger and Platt, 2002; Bruns et al., 2004, 2006, and references in the publication list given above).

For MAX-DOAS observations, the photon path length along the line of sight is limited by the atmospheric visibility; thus their sensitivity strongly depends on the aerosol optical depth. Therefore, the knowledge of the atmospheric aerosol properties is a prerequisite for the correct interpretation of MAX-DOAS measurements. However, in turn, from MAXDOAS observations of trace gases with constant (and known) concentration profiles (like for the oxygen molecule $\mathrm{O}_{2}$ or the oxygen dimer $\mathrm{O}_{4}$ (Greenblatt et al., 1990; Wagner et al., 2002)), information on atmospheric aerosol properties can be also retrieved (see e.g. Wagner et al., 2004; Wittrock et al., 2004, and references of the publication list given above).

The simulation of the MAX-DOAS geometry exhibits a particular challenge for RTMs because of the extended light
Table 1. Lower boundaries and vertical extensions of the atmospheric layers selected for the box-AMF calculation. Please note that above $1000 \mathrm{~m}$ the layers are thinner than the distances between the layers. If needed, box-AMFs for layers in between can be derived by interpolation.

\begin{tabular}{lll}
\hline Atmospheric layer & $\begin{array}{l}\text { Lower } \\
\text { boundary }\end{array}$ & $\begin{array}{l}\text { Vertical } \\
\text { extension }\end{array}$ \\
\hline 1 & ground & $100 \mathrm{~m}$ \\
2 & $100 \mathrm{~m}$ & $100 \mathrm{~m}$ \\
3 & $200 \mathrm{~m}$ & $100 \mathrm{~m}$ \\
4 & $300 \mathrm{~m}$ & $100 \mathrm{~m}$ \\
5 & $400 \mathrm{~m}$ & $100 \mathrm{~m}$ \\
6 & $500 \mathrm{~m}$ & $100 \mathrm{~m}$ \\
7 & $600 \mathrm{~m}$ & $100 \mathrm{~m}$ \\
8 & $700 \mathrm{~m}$ & $100 \mathrm{~m}$ \\
9 & $800 \mathrm{~m}$ & $100 \mathrm{~m}$ \\
10 & $900 \mathrm{~m}$ & $100 \mathrm{~m}$ \\
11 & $1000 \mathrm{~m}$ & $100 \mathrm{~m}$ \\
12 & $1500 \mathrm{~m}$ & $100 \mathrm{~m}$ \\
13 & $2000 \mathrm{~m}$ & $100 \mathrm{~m}$ \\
14 & $3000 \mathrm{~m}$ & $100 \mathrm{~m}$ \\
15 & $5000 \mathrm{~m}$ & $100 \mathrm{~m}$ \\
16 & $10000 \mathrm{~m}$ & $1000 \mathrm{~m}$ \\
17 & $20000 \mathrm{~m}$ & $1000 \mathrm{~m}$ \\
\hline
\end{tabular}

paths through the lowest atmospheric layers. For such slant lines of sight, the correct treatment of the Earth's sphericity can become important. Moreover, the optical depth with respect to Rayleigh and aerosol scattering can become very large and the correct implementation of multiple scattering becomes indispensable.

The particular aims of this comparison exercise include the following aspects:

A) The comparison of current RTMs from different research groups and quantification of the differences.

B) The identification of shortcomings and the assessment of the uncertainties of the model results.

C) The investigation of the sensitivity of MAX-DOAS observations for different viewing geometries with a particular focus on the influence of aerosols. In Sect. 4.1 the response to variations of the elevation angle of the telescope (with respect to the horizon) is investigated; in Sect. 4.2 a similar sensitivity study is performed for the relative azimuth angle (the angle between the projections of the viewing direction and the direction of the sun to the surface).

D) The provision of a consolidated set of box-AMFs for selected atmospheric conditions: these box-AMFs allow the calculation of (total) AMFs for any kind of atmospheric trace gas profiles fitting in the used layer pattern.

E) The definition and documentation of basic atmospheric reference scenarios. These scenarios (together with the model results) are ideal test cases for future RTM developments. 
Table 2. Overview on the participating models and some important properties.

\begin{tabular}{|c|c|c|c|}
\hline Model/Institute & Type & Treatment of sphericity & Refraction \\
\hline MODTRAN/Switzerland & discrete ordinate approach & spherical & yes \\
\hline MCC++/Russia & Backward Monte Carlo & spherical & partly \\
\hline MCARaTS/Japan & Forward Monte Carlo & $\begin{array}{l}\text { plane-parallel for the direct solar } \\
\text { beam } \\
\text { spherical for the line of sight: } \\
\text { plane-parallel for the diffuse radiation }\end{array}$ & yes \\
\hline PROMSAR/Italy & Backward Monte Carlo & spherical & no \\
\hline UVspec/DISORT/Belgium & discrete ordinate approach & $\begin{array}{l}\text { spherical for direct solar beam } \\
\text { plane parallel for multiple scattering } \\
\text { plane parallel for integration along } \\
\text { the line of sight }\end{array}$ & Not applied \\
\hline VECTOR/Canada & $\begin{array}{l}\text { technique of successive orders of } \\
\text { scattering }\end{array}$ & $\begin{array}{l}\text { spherical for direct solar beam } \\
\text { plane parallel for multiple scattering } \\
\text { spherical for integration along the line } \\
\text { of sight }\end{array}$ & no \\
\hline $\begin{array}{l}\text { SCIATRAN/Bremen } \\
\text { plane parallel }\end{array}$ & Discrete Ordinate Method & Plane parallel & Not applied \\
\hline $\begin{array}{l}\text { SCIATRAN/Bremen } \\
\text { spherical }\end{array}$ & $\begin{array}{l}\text { Discrete Ordinate Method for multi- } \\
\text { ple scattering (plane parallel) } \\
\text { characteristics method for integration } \\
\text { along the line of sight (spherical) }\end{array}$ & $\begin{array}{l}\text { spherical for direct solar beam } \\
\text { pseudo-spherical for multiple scatter- } \\
\text { ing } \\
\text { spherical for single scattering } \\
\text { spherical for integration along the line } \\
\text { of sight }\end{array}$ & yes \\
\hline TRACY-II/Heidelberg & Backward Monte Carlo & spherical & partly (see text) \\
\hline
\end{tabular}

The paper is organised as follows. First the participating models are introduced (Sect. 2) and the basic specifications of important input parameters for the RTM comparison are described (Sect. 3.1). In Sect. 3.2, basic model results for simple atmospheric scenarios are compared in order to identify possible elementary errors. In the following main part of the comparison exercise (Sects. 4.1-4.3) the normalised radiances and box-AMFs for MAX-DOAS observations at different atmospheric scenarios are presented. Finally, case studies for a changed surface albedo and aerosol scattering phase function are presented (Sects. 4.4-4.5).

\section{Description of the participating models}

Nine models from eight international research groups took part in the comparison exercise. All models included multiple scattering schemes. Besides the way they solve the radiative transfer equation, they also differ in their treatment of the Earth's curvature and refraction. In the following subsections the individual models are briefly described. The basic features are summarised in Table 2.
2.1 MODTRAN, Paul Scherrer Institut, Villigen, Switzerland

MODTRAN 4 is a commercially available atmospheric radiative transfer model developed jointly by Spectral Sciences, Inc. and the Air Force Research Laboratory/Space Vehicles Division (AFRL/VS). This software is based on LOWTRAN 7, but exhibits many improvements and new features (Acharya, 1999; Berk, 2000; Berk, 1999). Both models calculate atmospheric transmittance, single scattered solar radiance, direct solar irradiance, and multiple scattered solar and thermal radiances. The spectral resolutions of LOWTRAN 7 and MODTRAN 4 in the spectral range of 0 to $50000 \mathrm{~cm}^{-1}$ ( $\infty$ to $200 \mathrm{~nm}$ ) are $20 \mathrm{~cm}^{-1}$ and $2 \mathrm{~cm}^{-1}$, respectively. The standard output of MODTRAN 4 consists of spectrally resolved transmittances, optical depths, radiances, and fluxes split into their components (e.g. transmittance of various constituents, direct and scattered radiation).

The version v3r1 of the RTM (released in May 2003), which is currently used at PSI, provides two schemes to compute multiple scattering: an approximate 2-stream algorithm and the DISORT N-stream option. The ground surface is specified either as Lambertian or includes the effects of various Bidirectional Reflectance Distribution Functions (BRDFs). Adjacency effects are supported as well. Various degrees of complexity are supported to define aerosol input 
data ranging from selecting different built-in haze models (e.g. rural extinction) to explicit input profiles of extinction and absorption coefficients as well as phase functions. A separate Mie code is available to compute these optical parameters if the size distributions of aerosols are known. MODTRAN 4 supports various geometric conditions and their input options: light paths between two heights, from ground to space and vice versa, as well as limb viewing.

For this comparison exercise, the vertical atmospheric profiles are specified for 49 layers. Layer tops in $\mathrm{km}$ are located at the following heights: $0.5,1.0,1.001,2.02 .001 \mathrm{~km} ; 3$ to 25 in steps of $1 \mathrm{~km} ; 25$ to $50 \mathrm{~km}$ in steps of $2.5 \mathrm{~km} ; 50$ to $100 \mathrm{~km}$ in steps of $5 \mathrm{~km}$. For the ozone cross sections the high-resolution values integrated in the spectral data base were used. The difference between those data and the figures specified for the inter-comparison range from 5 to $40 \%$, depending on wavelength.

Only 2 output parameters of standard MODTRAN 4 are compatible with the quantities specified for the MAX-DOAS RTM inter-comparison: radiance and vertical optical depth. In particular, MODTRAN 4 is not devised to calculate box air mass factors. Radiance could easily been normalised by the built-in solar spectrum at the top of the atmosphere. However, theses quantities may substantially fluctuate with wavelength. Hence, we averaged the values for the nominal wavelength $\lambda$ over the interval $[\lambda-1 \mathrm{~nm}, \lambda+1 \mathrm{~nm}]$. Due to these restrictions, only the normalised radiance and the vertical optical depth are listed in the inter-comparison data files.

\subsection{MCC++, Obukhov Institute of Atmospheric Physics,} Moscow, Russia

MCC++ is a combination of the Monte Carlo method to simulate multiple scattering with the direct integration procedure to simulate single scattering (Postylyakov et al., 2001; Postylyakov, 2003, 2004a, b). This combination makes optimum use of the computing resources. To simulate multiple scattering, the MCC++ code may employ two Monte Carlo methods, the method of conjugate walk (in other words "backward simulation") or the modified double local estimation (used for simulation of twilight) (Marchuk et al., 1980). To compute the single scattering radiance, a procedure of direct integration of the source function is realised in line with the Monte Carlo one. An approximation of the spherically symmetrical atmosphere is applied to further shorten the time of the simulation. A quick algorithm for simultaneous evaluation of effective box-AMFs together with radiance was implemented in the model. The MCC++ code has vector (with polarisation) and scalar versions, and takes into account surface albedo (Lambertian and the BRDF), aerosol scattering and absorption. Atmospheric refraction may be taken into account except for the photon way from the last scattering point. The model is coded in $\mathrm{C}++$, which makes it possible to release like the $\mathrm{C}++$ templates different versions of the algorithm and widely to use code recycling. The vertical grid uses $100 \mathrm{~m}$ steps from 0 to $10 \mathrm{~km}, 1 \mathrm{~km}$ steps from 10 to $45 \mathrm{~km}$, and $5 \mathrm{~km}$ steps from 45 to $100 \mathrm{~km}$.

\subsection{MCARaTS, Frontier Research Center for Global} Change, Japan Agency for Marine Earth Science and Technology, Yokohama, Japan

The Monte Carlo Atmospheric Radiative Transfer Simulator (MCARaTS) is a parallelised three-dimensional radiative transfer model, being based on the forward-propagating Monte Carlo photon transport algorithm (Iwabuchi, 2006). The model was developed at FRCGC/JAMSTEC, Japan, to study the energy budget in a cloudy atmosphere and remote sensing of gases, aerosols and clouds. Radiation sources can be solar radiation, thermal emission, or any point source (e.g. artificial lamps, laser beams etc). Radiances are calculated by integrating the contributions from each event of scattering or source emission, according to the local estimation method (Marchuk et al., 1980). The box AMF is obtained as intensity-weighted average path length for a given layer. The current version employs a Cartesian coordinate system and cyclic boundary conditions. Multiple scattering, atmospheric refraction, and finite solar disk are taken into account. The atmospheric curvature is taken into account for the integration along the line of sight. Numerical efficiency is highly optimised by several variance reduction techniques. In the inter-comparison exercises, a collisionforcing method for efficient computations in optically thin media is used. The top of model atmosphere was set to $100 \mathrm{~km}$, and layer spacing was $100 \mathrm{~m}$ below an altitude of $5.1 \mathrm{~km}$. A serial code ran on a modern personal computer, where each experiment traced $10^{6}$ trajectories. More information on the model can be found on the web (at present, http://www.geocities.jp/null2unity/mcarats/).

2.4 PROMSAR code for the Monte Carlo simulation of the radiation transport in the atmosphere, Institute of Atmospheric Science and Climate, Bologna, Italy

PROMSAR (PROcessing of Multi-Scattered Atmospheric Radiation) is a backward Monte Carlo code for atmospheric radiative transfer (Palazzi et al., 2005).

The procedure for each photon is initiated by releasing it from the detector in the line of sight direction and is followed in a direction which is opposite to that in which the photon would physically propagate. Two different methods are used to sample the distance (free optical path) between the detector and the collision point as well as the successive collisions that occur along the photon's backward path. They are distinguished by whether the photon extended path intersects the surface or not. In the first case the photon can be reflected by the ground (Lambertian surface) and the free optical path is sampled from an exponential distribution. In the second case, a collision is forced before the photon escapes the atmosphere and a truncated exponential distribution is used 
(Collins et al., 1972). This forced collision technique is one of the variance reducing methods and it is used to reduce the computational time and keep the statistical oscillations relatively small.

A photon weight is assigned to each photon and reduced at each interaction. The photon statistical weight is adjusted to removed the bias introduced when a collision is forced to occur. A photon history is terminated when the weight falls below a specified threshold value.

The atmosphere is modelled with a spherical 2-D multilayer geometry in which the optical parameters, varying from layer to layer, can be read in an input library together with information on the vertical layering of the atmosphere. The source for this input library is MODTRAN code, which has been conveniently adapted, so as to exploit the large variety of atmospheric scenarios and climatologic choices present in it. The MODTRAN vertical layering of atmosphere $(1 \mathrm{~km}$ between 0 and $25 \mathrm{~km}, 2.5 \mathrm{~km}$ between 25 and $50 \mathrm{~km}$ and $5 \mathrm{~km}$ between 50 and $120 \mathrm{~km}$ ) can however be modified running PROMSAR and be set according to the specific aims. In the current version of PROMSAR refraction has not been implemented.

What PROMSAR uses to calculate AMFs is the mean path of the photons in the atmosphere layer by layer, (averaged on all the photon histories) and the a priori vertical profile of the absorber of interest:

$$
\mathrm{AMF}=\frac{\sum_{0}^{\mathrm{TOA}} \Delta S_{i} \cdot \rho_{i}}{\sum_{0}^{\mathrm{TOA}} \mathrm{VCD}_{i}}
$$

Here $\Delta \mathrm{S}_{i}$ and $\rho_{i}$ refer to the averaged path and the trace gas concentration in the layer $\mathrm{i}$ and the sum is carried out from the surface to the TOA (top of the atmosphere).

For this MAX-DOAS RTM comparison the vertical discretisation chosen for the calculation of the box-AMFs was the same as shown in Table 1 and the upper limit of the atmosphere was set to $100 \mathrm{~km}$. The number of photons processed was $10^{5}$, representing a good trade off between statistical significance and reasonable computational times.

\subsection{UVspec/DISORT, Institut d'Aéronomie Spatiale de Belgique, Brussels, Belgium}

The RT model used by IASB for this comparison exercise is a modified version of the UVSPEC/DISORT package. A detailed description of this model - which is freely available at http://www.libradtran.org - can be found in Mayer and Kylling (2005). In brief, the RT equation is solved using the discrete ordinate approach. The DISORT solver includes a pseudo-spherical correction which treats the direct solar beam in spherical geometry and multiple scattering in planeparallel approximation. The atmospheric constituents are divided into five classes: Rayleigh-scattering by air molecules, molecular absorption, aerosol, water and ice clouds. Treatments for ground albedo (Lambertian reflector) and refraction are also included. The vertical discretisation is freely adjustable by the user. For the present exercise, the following vertical grid was used: $0-6 \mathrm{~km}$ : $100 \mathrm{~m}$ steps, $7-90 \mathrm{~km}$ : $1 \mathrm{~km}$ steps.

\subsection{VECTOR, Environment Canada, Toronto, Canada}

VECTOR, or Vector Orders-of Scattering Radiative Transfer model, is based on the McLinden et al. (2000, 2002) model with updates described in McLinden et al. (2006). VECTOR solves the vector radiative transfer equation (VRTE) using the technique of successive orders of scattering. It is solved for an arbitrary viewing geometry as follows. Based on specified viewing location and direction, the range in solar zenith angles is calculated and a sub-set of these is selected. At each of these selected SZAs an atmosphere and a surface albedo are specified and a plane-parallel calculation is performed. From this, vertical profiles of the multiple-scattered source function and extinction coefficient are obtained. The vector radiance is calculated by integrating the VRTE along the observing line-of-sight through a spherical shell atmosphere, using at each point the appropriate plane-parallel source function vector and extinction coefficient for the local SZA. VECTOR is also coupled to a line-by-line code with options for full numerical calculation of the Voigt lineshape or one of several approximations (e.g., Humlièek). For this comparison exercise, VECTOR is run in scalar mode. An initial calculation is made using the prescribed atmosphere and then the absorber (ozone) is successively perturbed at all altitudes considered in this study. See Bassford et al. (2001) for additional information on the application of VECTOR to AMFs.

\subsection{SCIATRAN, Institut für Umweltphysik, University of Bremen, Bremen, Germany}

The radiative transfer model SCIATRAN used in the comparisons is a part of the newest software package SCIATRAN 2.2 (Rozanov et al., 2005; Rozanov, 2004-2006). In the spherical mode the model employs the newly developed CDI-D approach based on the Combined Differential Integral technique well known from previous versions of the SCIATRAN model (Rozanov et al., 2000, 2001, 2005). Additionally a Fourier series expansion is employed. As before the intensity of the radiation is calculated solving the radiative transfer equation (RTE) in a spherical atmosphere in its integral form employing the characteristics method. This means that the source function is integrated along the line of sight intersecting a spherical atmosphere. The single scattering part of the source function is truly spherical and the multiple scattering part is initialised by the output of the pseudo-spherical model. Unlike previous versions, the pseudo-spherical radiative field is obtained employing the 
Discrete Ordinates method. Both integro-differential radiative transfer equation in a pseudo-spherical atmosphere and spherical integral RTE are solved for each Fourier term independently. The weighting functions are calculated employing a solution of the adjoint RTE. Similar to the intensity the adjoint intensity is initialised in the pseudo-spherical approximation and then used to obtain the spherical weighting functions. In the plane-parallel mode the integro-differential radiative transfer equation is solved in a plane-parallel atmosphere using the Discrete ordinate method for each Fourier term independently. The weighting functions are obtained employing the solution of the adjoint plane-parallel radiative transfer equation. The box air mass factors are derived from the weighting functions using the following formula:

$$
\mathrm{AMF}=-\mathrm{WF} \cdot c / I / d z / \sigma
$$

where WF is the absolute weighting function (change of radiance in response to a change in absorber concentration), $c$ is the trace gas number density, $I$ is the intensity of the radiance, $d z$ is the geometrical thickness of the vertical layer and $\sigma$ is the trace gas cross section.

2.8 TRACY, Institut für Umweltphysik, University of Heidelberg, Heidelberg, Germany

TRACY is based on the backward Monte Carlo method: a photon emerges from a detector in an arbitrary line of sight direction and is followed in the backward direction along the path until the photon leaves the top of the atmosphere. The various events which may happen to the photon at various altitudes are defined by suitable probability distributions. Random numbers decide on the occurrence of events. At each scattering event the probability that the photon is scattered into the sun is calculated and the intensity of the photon is weighted by the sum of the probabilities of all scattering events (local estimation method, see Marchuk et al., 1980). A large number of random photon paths is generated reproducing the light contributing to the simulated measurement. The box-AMFs are calculated from the modelled radiances with (I) and without $\left(\mathrm{I}_{0}\right)$ the absorber of interest:

$\mathrm{AMF}_{i}=\frac{\ln \left(I_{0} / I\right)}{\mathrm{VCD}_{i} \cdot \sigma}$

with $\sigma$ being the absorption cross section of the considered trace gas and $\mathrm{AMF}_{i}$ and $\mathrm{VCD}_{i}$ being the box-AMF and vertical column density for the (constant) trace gas concentration at layer i, respectively. For this comparison exercise an updated version (TRACY-II) of the version described in von Friedeburg (2003) is used. For details of the new version TRACY-II, see Deutschmann et al. (2006). For TRACY-II, refraction is not yet fully included: the rays from the scattering points to the sun are calculated without refraction. This should, however, have only a negligible effect, since the calculations of this exercise are performed for small or moderate solar zenith angles (see Table 5). In addition to TRACY-II we performed the comparison exercises also with the original version (TRACY-I, see von Friedeburg, 2003; Hendrick et al., 2006). The box-AMFs of TRACY-I showed almost the same values as for TRACY-II; the normalised radiances of TRACY-I, however, showed systematically too high values.

\section{Basic settings and tests}

Before the specific MAX-DOAS geometries are simulated by the models (Sect. 4), some basic model parameters were prescribed and also selected model results were compared for basic cases. In this way it was possible to identify and correct (simple) errors of individual models.

\subsection{Definition of model scenarios}

In order to allow a meaningful interpretation of the RTM results, several basic properties were set to predefined values for all models. For the temperature and pressure profiles the data from the US standard atmosphere were used (United States Committee on Extension to the Standard Atmosphere, 1976). The temperature was interpolated linearly to match the vertical discretisation of the individual models; for the pressure the logarithm was interpolated linearly. No instructions were given for the setting of numerical parameters (e.g., vertical or angular discretisation). The ozone cross section measured with the SCIAMACHY instrument (Bogumil et al., 2003) was used (see Table 3); all other atmospheric absorbers were ignored. The exercises were carried out for five wavelengths covering regions of the UV and visible spectral range, where important trace gases show characteristic absorptions (see Table 3). To minimise any complications due to different telescope apertures, the field of view was set to very small values $\left(<0.1^{\circ}\right)$.

It should be noted that in contrast to the observation of zenith scattered light at large solar zenith angles, the influence of atmospheric refraction on MAX-DOAS observations is typically small. Even in the case of very long lines of sight (e.g. for $577 \mathrm{~nm}$, elevation angle of $1^{\circ}$, no aerosol, see Sect. 4.3), the effect is at maximum a few percent. For typical atmospheric situations and measurement geometries it is negligible. Thus for this comparison exercise, the treatment of refraction in the individual models was not prescribed.

The RTM comparison was performed for five different aerosol scenarios including also a pure Rayleigh atmosphere (see Table 4). For the investigation of the dependence of the model results on the viewing direction of the telescope (see Sects. 4.1 and 4.2), specific viewing directions of the telescope were chosen as described in Table 5. 
Table 3. Wavelengths and ozone cross sections used in the RTM comparison exercise. The data are taken from Bogumil et al. (2003). Also shown are trace gases, which are typically analysed at the respective wavelengths.

\begin{tabular}{llllll}
\hline Wavelength $[\mathrm{nm}]$ & 310 & 360 & 440 & 477 & 577 \\
\hline $\mathrm{O}_{3}$ cross section $\left(\mathrm{cm}^{2}\right)$ & $9.59 \times 10^{-20}$ & $6.19 \times 10^{-23}$ & $1.36 \times 10^{-22}$ & $5.60 \times 10^{-22}$ & $4.87 \times 10^{-21}$ \\
Trace gases analysed in this spectral range & $\mathrm{SO}_{2}$ & $\mathrm{BrO}, \mathrm{HCHO}, \mathrm{O}_{4}$ & $\mathrm{NO}_{2}, \mathrm{IO}, \mathrm{CHOCHO}$ & $\mathrm{O}_{4}$ & $\mathrm{O}_{4}$ \\
\hline
\end{tabular}
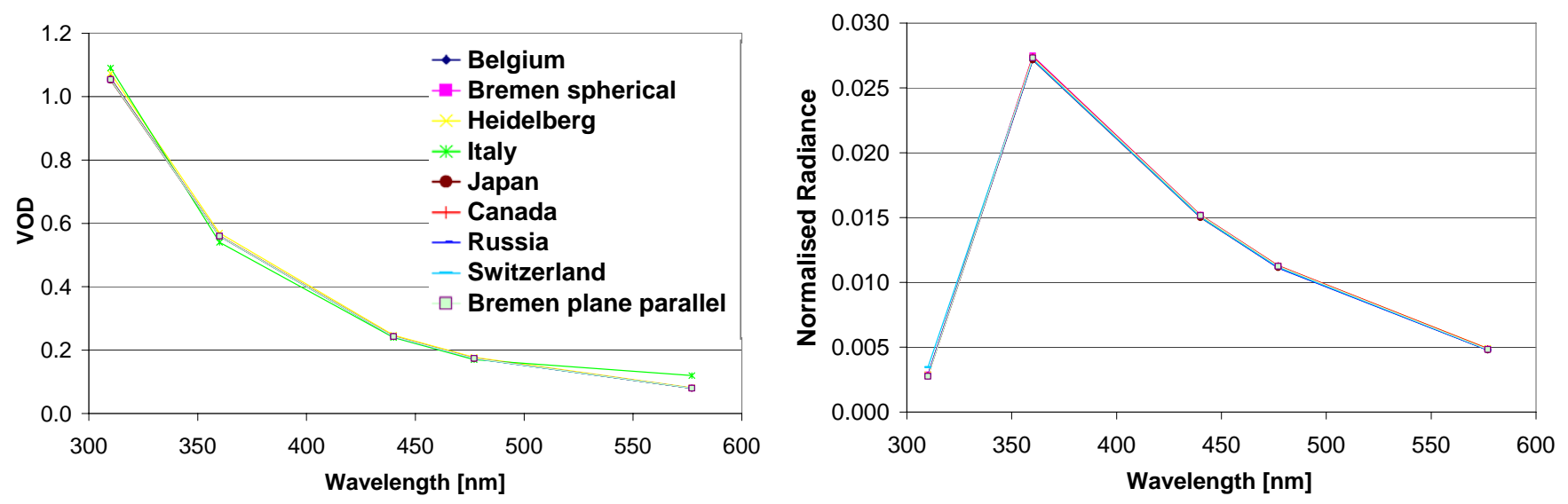

Fig. 1. Modelled vertical optical depth with respect to Rayleigh-scattering (left) and normalised radiances taking into account also ozone absorption (right) as a function of wavelength.

Table 4. Aerosol properties for the different test cases (Case A1 represents a pure Rayleigh-atmosphere). The asymmetry parameter was assumed to be independent from wavelength.

\begin{tabular}{llll}
\hline Case & $\begin{array}{l}\text { Aerosol } \\
\text { extinction } \\
\left(\mathrm{km}^{-1}\right)\end{array}$ & Altitude range & Asymmetry parameter \\
\hline A1 & 0 & - & - \\
A2 & 0.5 & $0-2 \mathrm{~km}$ & 0.68 (urban) \\
A3 & 0.1 & $0-1 \mathrm{~km}$ & 0.68 (urban) \\
A4 & 0.5 & $0-2 \mathrm{~km}$ & 0.75 (maritime) \\
A5 & 0.1 & $0-1 \mathrm{~km}$ & 0.75 (maritime) \\
\hline
\end{tabular}

\subsection{Basic test of the model properties (exercise 0)}

The first step of the RTM comparison was to check basic model results (like e.g. the vertical optical density of the atmosphere) for a simple viewing geometry. This check was performed to avoid any elementary mistakes, which would later complicate the interpretation of the results for the MAX-DOAS settings. Only Rayleigh-scattering was allowed. The zenith viewing geometry was chosen and the solar zenith angle (SZA) was set to $70^{\circ}$. The exercises were carried out for all five wavelengths (see Table 3).
Table 5. Overview of the solar zenith angles, the elevation and the relative azimuth angles of the telescope. Exercises were performed for specific combinations of these angles.

\begin{tabular}{ll}
\hline $\begin{array}{l}\text { Selected elevation angles } \\
\left(\text { SZA: } 20^{\circ}\right)\end{array}$ & $\begin{array}{l}\text { Selected relative azimuth an- } \\
\text { gles } \\
\left(\text { SZA: } 80^{\circ}\right)\end{array}$ \\
\hline $1^{\circ}$ & $0^{\circ}$ \\
$2^{\circ}$ & $30^{\circ}$ \\
$3^{\circ}$ & $60^{\circ}$ \\
$6^{\circ}$ & $90^{\circ}$ \\
$10^{\circ}$ & $120^{\circ}$ \\
$20^{\circ}$ & $150^{\circ}$ \\
$90^{\circ}$ & $180^{\circ}$ \\
\hline
\end{tabular}

In Fig. 1 the results for the vertical optical depth (with respect to Rayleigh-scattering) and the normalised radiances (taking into account Rayleigh-scattering and ozone absorption) are shown. The optical depth increases with decreasing wavelength as expected for the strong wavelength dependence of Rayleigh-scattering. Accordingly, the normalised radiances increase towards shorter wavelengths, but decrease again for the shortest wavelength $(310 \mathrm{~nm})$ because of the strong ozone absorption. The results for the optical depth are almost identical for all RTMs indicating that all models 

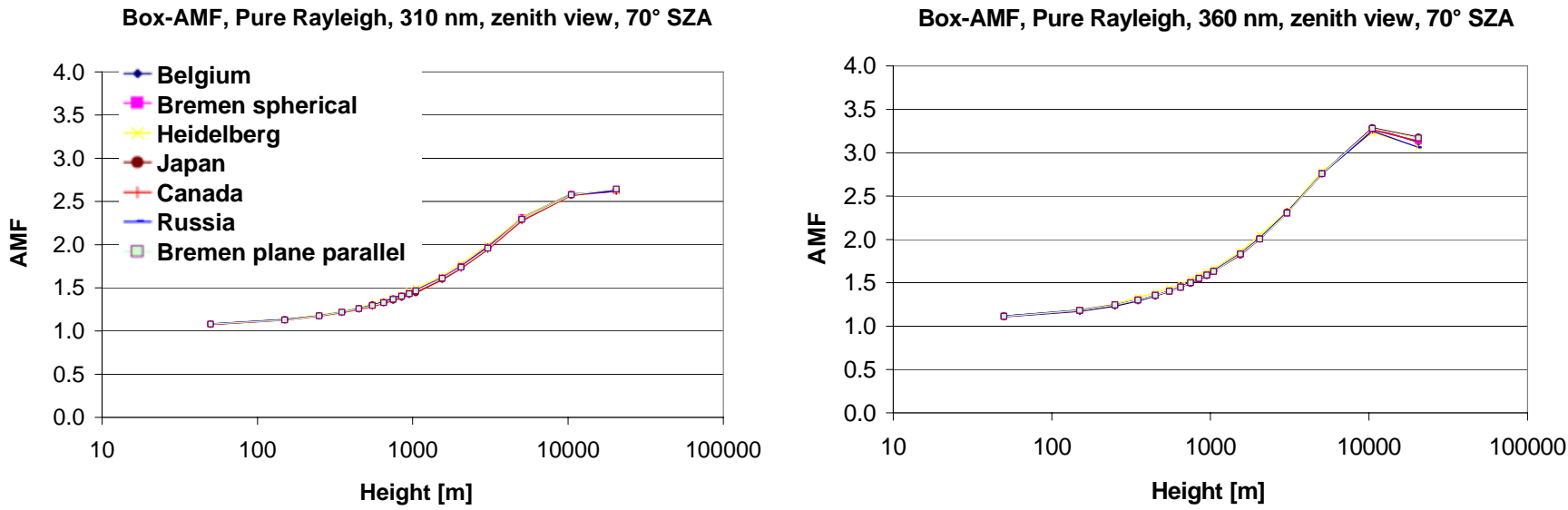

Box-AMF, Pure Rayleigh, $440 \mathrm{~nm}$, zenith view, $70^{\circ} \mathrm{SZA}$

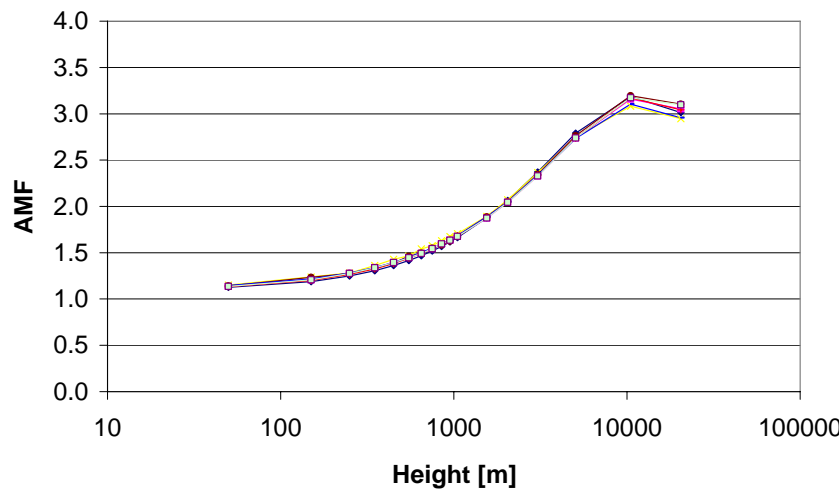

Box-AMF, Pure Rayleigh, $477 \mathrm{~nm}$, zenith view, $70^{\circ} \mathrm{SZA}$

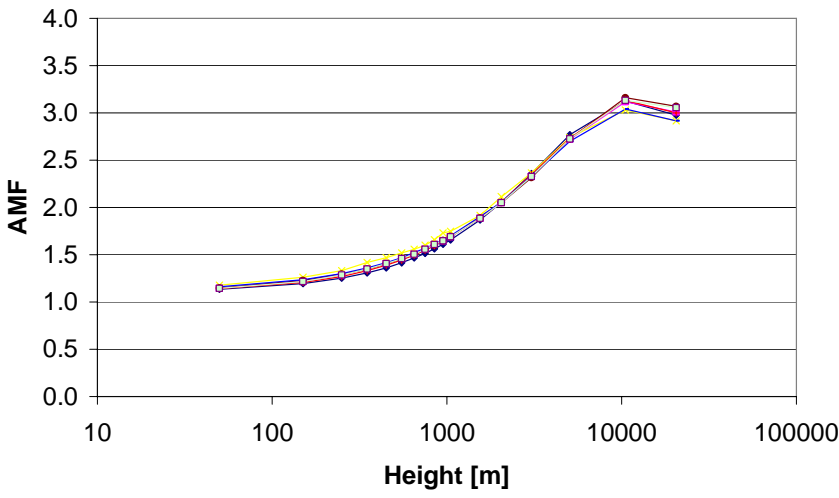

Box-AMF, Pure Rayleigh, 577 nm, zenith view, $70^{\circ}$ SZA

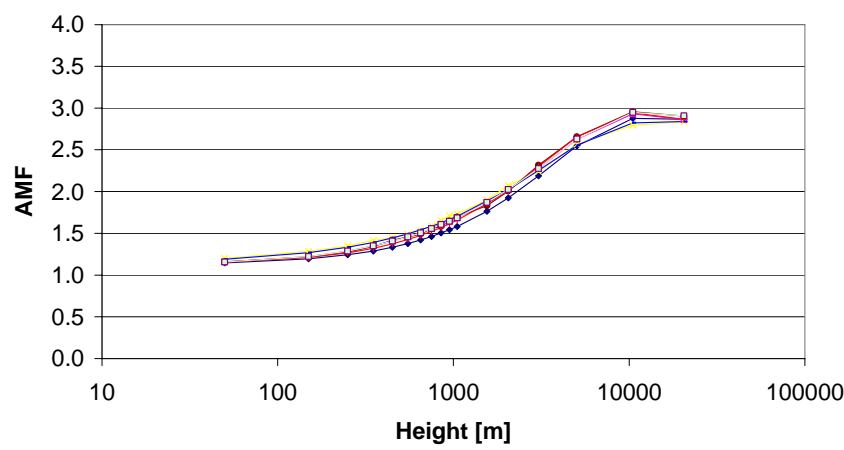

Fig. 2. Box-AMFs for zenith viewing geometry at a solar zenith angle of $70^{\circ}$. For low altitudes, the box-AMFs are about unity; for high altitudes about $1 / \cos (\mathrm{SZA}) \approx 2.9$. Please note that the altitude is displayed on a logarithmic scale.

treat Rayleigh-scattering consistently. Also the normalised radiances agree within a few percent.

In Fig. 2 the Box-AMFs derived from all models for zenith viewing geometry and a solar zenith angle of $70^{\circ}$ are displayed. For atmospheric layers at low altitudes, the box-AMFs are about unity, since the observed photons have traversed these layers almost exclusively on a vertical path. In contrast, the direction of the photons for the highest layers is determined by the direct solar beam (al- most all scattering events occur below). Thus, the boxAMF for these layers is similar to the geometrical approximation $\mathrm{AMF}=1 / \cos (\mathrm{SZA}) \approx 2.9$. For some wavelengths and altitudes, also values $>2.9$ are derived, indicating that multiple scattered photons enhance the geometrical light path. For the layers between the surface and $20 \mathrm{~km}$, part of the photons are already scattered above, part are scattered below and the box-AMF is between unity and 2.9. It is interesting to note that at $310 \mathrm{~nm}$ even for the highest altitudes values $<2.9$ 

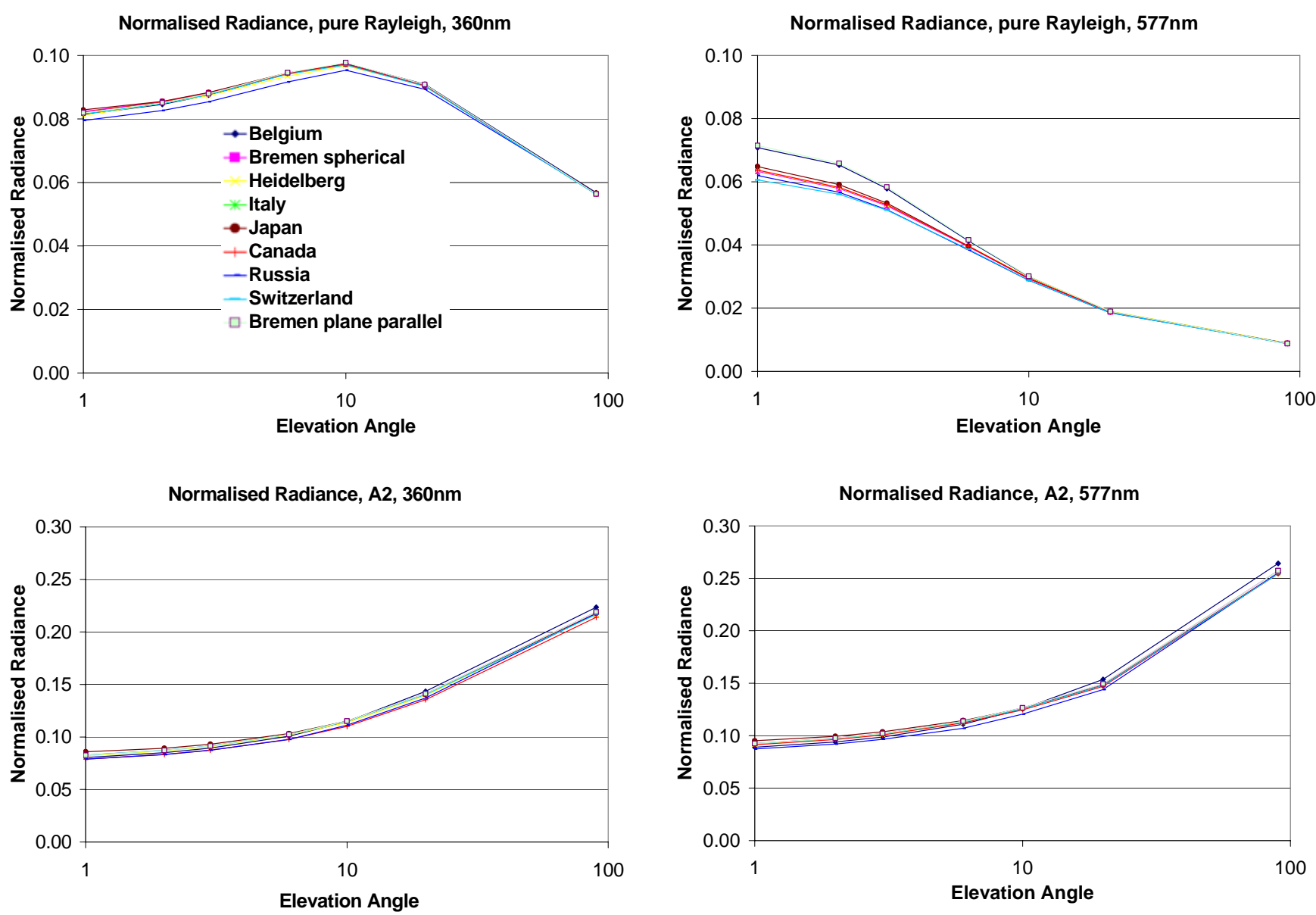

Fig. 3. Modelled normalised radiances at $360 \mathrm{~nm}$ (left) and $577 \mathrm{~nm}$ (right) for a pure Rayleigh-atmosphere (top) and including also aerosols (bottom). For the aerosols, scenario "A2" was used with an extinction of $0.5 \mathrm{~km}^{-1}$ between the surface and $2 \mathrm{~km}$ (see Table 4 ). The SZA was $20^{\circ}$ and the relative azimuth angle $0^{\circ}$. The normalised radiances are displayed as a function of the elevation angle (on a logarithmic scale).

occur, indicating that a substantial fraction of the observed photons is scattered above $20 \mathrm{~km}$.

From this test of the basic model parameters we conclude that all RTMs work with similar prerequisites. The differences in the modelled optical depths and the normalised radiances are within only a few percent. Also the agreement of the modelled box-AMFs from the different models is good (within $5 \%$ or better); the differences might be at least partly explained by the way in which Earth's sphericity is treated (see also Sect. 4.3).

\section{Results for the MAX-DOAS case studies}

MAX-DOAS observations make use of the fact that the sensitivity for the surface-near layers strongly depends on the viewing geometry. In the following two exercises, we explore in detail the dependencies on the elevation and azimuth angle of the telescope.
4.1 Variation of the elevation angle of the telescope (exercise 1)

The major characteristic of MAX-DOAS measurements is that the illuminated sky is observed under different elevation angles of the telescope. For low elevation angles the path length in the lowest part of the atmosphere is significantly longer than for higher elevation angles (e.g. zenith view). Accordingly, the sensitivity for the boundary layer increases with decreasing elevation angle. However, it must be noted that the photon path length along the line of sight (and thus the sensitivity towards trace gases in the boundary layer) is limited by the atmospheric visibility. In general, the visibility is decreasing towards smaller wavelengths because of the strong wavelength dependence of Rayleigh-scattering. Moreover, especially for polluted situations, aerosol scattering further reduces the visibility; thus MAX-DOAS observations are very sensitive to the atmospheric aerosol load. Within this comparison exercise, we investigated atmospheric scenarios with and without aerosol 
scattering (aerosol scenario A2 was used, see Table 4). The calculations are performed for 7 elevation angles between $1^{\circ}$ and $90^{\circ}$, see Table 5. The solar zenith angle is set to $20^{\circ}$ and the relative azimuth angle is set to zero. We restrict the calculations to two wavelengths $(360 \mathrm{~nm}, 577 \mathrm{~nm})$ in order to minimise the computational effort.

In Fig. 3 the normalised radiances (at $360 \mathrm{~nm}$ and $577 \mathrm{~nm}$ ) for a pure Rayleigh-atmosphere and for aerosol scenario A2 are shown as a function of the elevation angle of the telescope. For the observation of scattered sunlight, the observed radiance depends on two major factors: first, on the optical depth along the line of sight. For small optical depths, the probability for photons to be scattered into the telescope (and thus the received intensity) increases with increasing geometrical length of the line of sight (decreasing elevation angle). For thick optical depths, the intensity becomes almost independent of the elevation angle. Second, the intensity also depends on the phase function for the relative angle between the telescope and the sun (if most photons are multiply scattered, the importance of this second factor decreases). For MAX-DOAS observations, typically (for small SZA like $20^{\circ}$ ) the phase function for Rayleigh-scattering increases with increasing elevation angle.

For our model scenario at $360 \mathrm{~nm}$, the optical depth along the line of sight remains high for a large range of elevation angles (it is $>3$ for elevation angles between $1^{\circ}$ and $10^{\circ}$ ); thus, for these elevation angles the normalised radiance is mainly determined by the increase in the phase function with elevation angle; for larger elevation angles, however, the optical depth strongly decreases leading to an overall decrease of the normalised radiance for $360 \mathrm{~nm}$.

For $577 \mathrm{~nm}$, the optical depth along the line of sight is much smaller than for $360 \mathrm{~nm}$ (it is $>3$ only for elevation angles between $1^{\circ}$ and $2^{\circ}$ ); thus the decrease in optical depth with increasing elevation angle determines the modelled normalised radiances over the whole range of elevation angles.

If aerosols are present, the situation changes completely. First, the optical depth along the line of sight is substantially increased (the optical depth is $>3$ for $1^{\circ}$ to $30^{\circ}$ at $360 \mathrm{~nm}$ and for $1^{\circ}$ to $10^{\circ}$ at $577 \mathrm{~nm}$ ). Moreover, the phase function of the aerosol scattering has a pronounced forward peak. Both factors cause a monotonous increase of the normalised radiance with increasing elevation angle over the whole range of elevation angles (it should be noted that this dependence can be different for relative azimuth angles other than zero).

For most cases, the normalised radiances of all models agree within about 5\%. However, larger deviations are found for the exercise at $577 \mathrm{~nm}$ for the pure Rayleigh-atmosphere. For this case, the path lengths along the line of sight become largest; consequently, also the influence of the Earth's sphericity becomes important. Two sets of models are evident. For the models using plane parallel geometry (Belgium, Bremen pane parallel), the altitude does increase more slowly with distance along the line of sight. Thus, the optical depth along the line of sight and also the normalised radiance becomes systematically larger than for the models using spherical geometry.

The results for the box-AMFs are shown in Figs. 4 and 5. As expected, the largest values are found for the smallest elevation angles and the lowest atmospheric layers. Especially for low extinction along the line of sight (in particular without aerosols) the box-AMFs for the lowest layers become very large ( $>40$, the geometrical approximation for a plane parallel atmosphere and an elevation angle would be $\left.1 / \sin \left(1^{\circ}\right) \approx 57\right)$. These strongly extended absorption paths cause the high sensitivity of MAX-DOASobservations for the boundary layer. For larger elevation angles, the box-AMFs for the lowest atmospheric layers decrease monotonously. For the highest atmospheric layers, the box-AMF converges towards the geometrical approximation for a solar zenith angle of $20^{\circ}\left(1 / \cos \left(20^{\circ}\right) \approx 1.06\right)$. If no aerosols are present, the box-AMFs decrease systematically with increasing altitude, indicating that an increasing number of photons has been scattered below that altitude.

If aerosols are present, two major changes can be observed. First, the box-AMFs for the lowest atmospheric layers become systematically smaller (this makes MAXDOAS observations particularly sensitive to aerosol properties (Wagner et al., 2004; Wittrock et al., 2004; Heckel et al., 2005; Sinreich et al., 2005; Frieß et al., 2006; Oetjen et al., 2006; Wittrock, 2006). Second, multiple scattering on aerosols can cause an enhancement of the box-AMFs for atmospheric layers in and directly above the aerosol layer; consequently, the box-AMFs for these layers are slightly enhanced (compared to the layers above). This effect can be best observed for high elevation angles, particularly for zenith direction, for which the highest box-AMFs are found for altitudes between $1 \mathrm{~km}$ and $5 \mathrm{~km}$ (Figs. 4 and 5 , bottom, right).

In general, again very good agreement (differences < $<\%$ ) is found for most of the cases (one exception is the Italian model, for which systematic differences from the other models occur especially for large elevation angles. The reason for this finding is still under investigation). As for the normalised radiances, systematic differences occur for the exercise for a pure Rayleigh-atmosphere and $577 \mathrm{~nm}$. For these cases, the path length along the line of sight becomes very long and thus the influence of the Earth's sphericity becomes especially important. The line of sight of the models using plane parallel geometry stays closer at the surface for larger distances from the instrument, causing systematically larger box-AMFs for low elevation angles.

\subsection{Variation of the azimuth angle (exercise 2)}

The relative azimuth angle between the direction of the telescope and the sun has an important influence on the amount of observed photons which are only scattered once (to a lesser degree also on photons which are scattered only a few times). The probability of these photons to be scattered into 

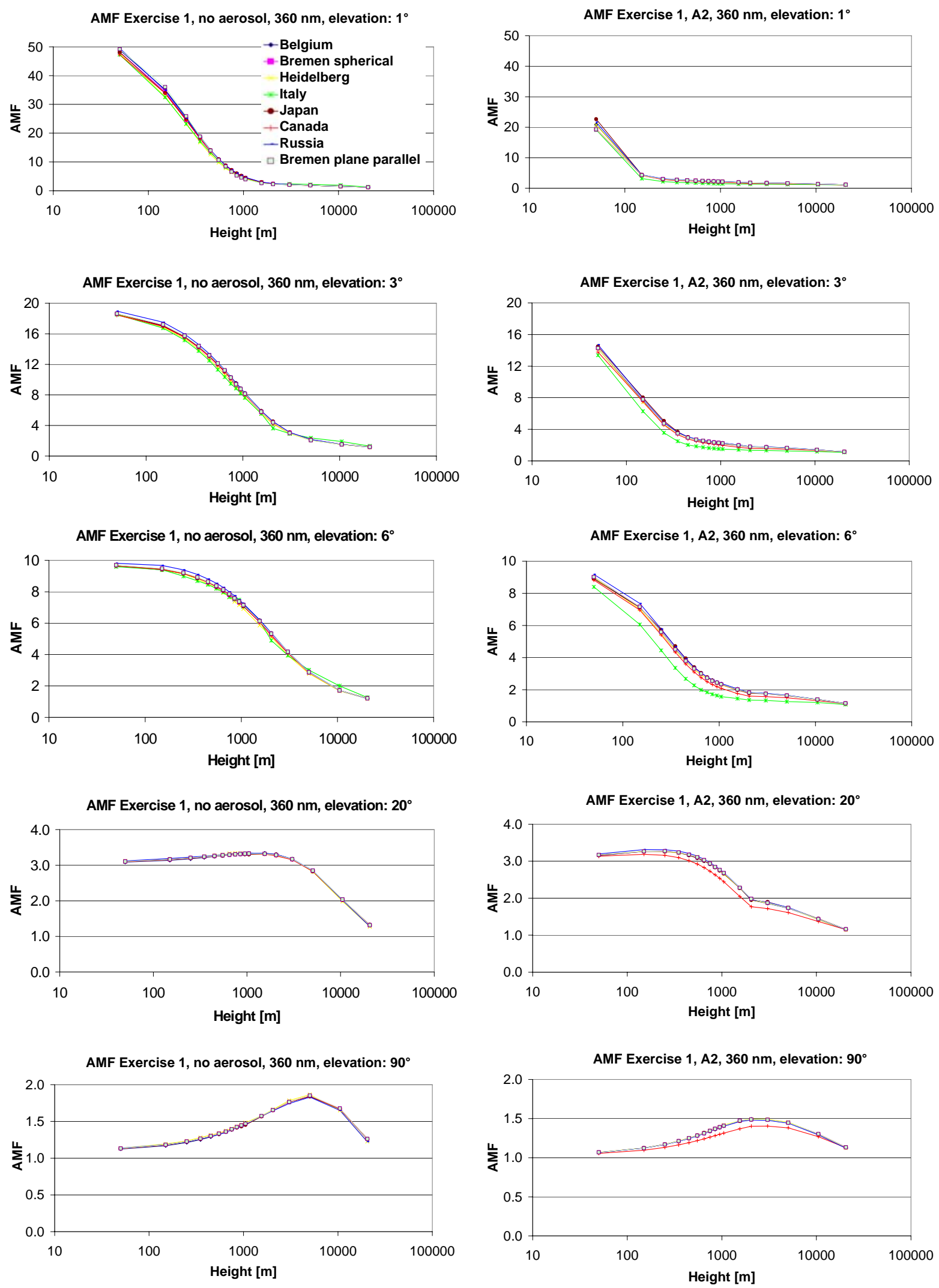

Fig. 4. Box-AMFs for $360 \mathrm{~nm}$ as a function of altitude (logarithmic scale). Left: pure Rayleigh-atmosphere. Right: including also aerosol scattering (scenario A2, see Table 4). From top to bottom the elevation angle increases from $1^{\circ}$ to $90^{\circ}$. 
AMF Exercise 1, no aerosol, $577 \mathrm{~nm}$, elevation: $1^{\circ}$

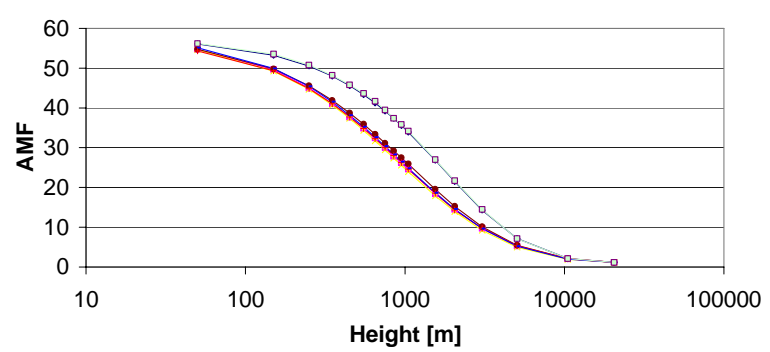

AMF Exercise 1, no aerosol, $577 \mathrm{~nm}$, elevation: $3^{\circ}$

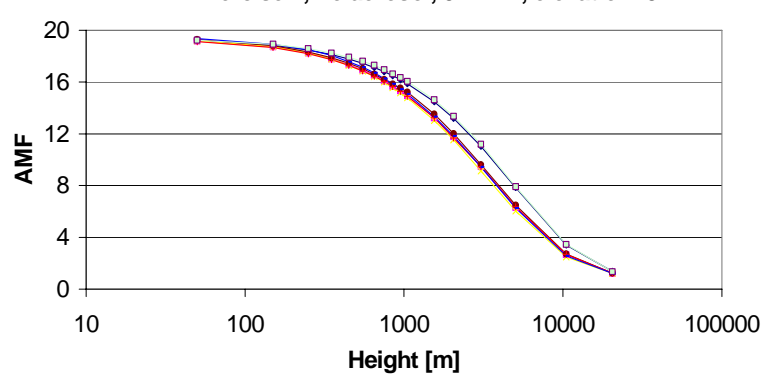

AMF Exercise 1, no aerosol, $577 \mathrm{~nm}$, elevation: $6^{\circ}$

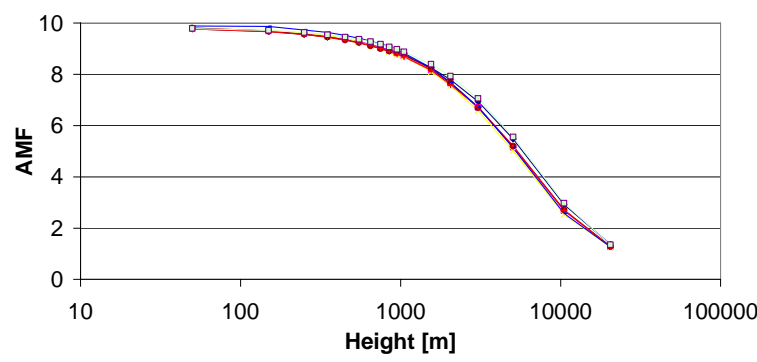

AMF Exercise 1, no aerosol, $577 \mathrm{~nm}$, elevation: $20^{\circ}$

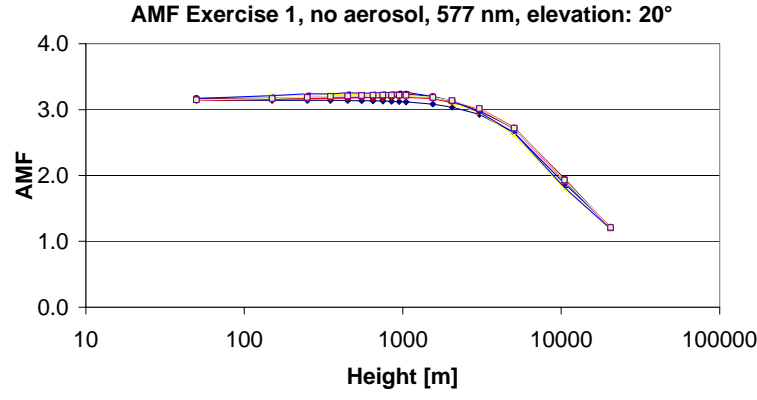

AMF Exercise 1, no aerosol, $577 \mathrm{~nm}$, elevation: $90^{\circ}$

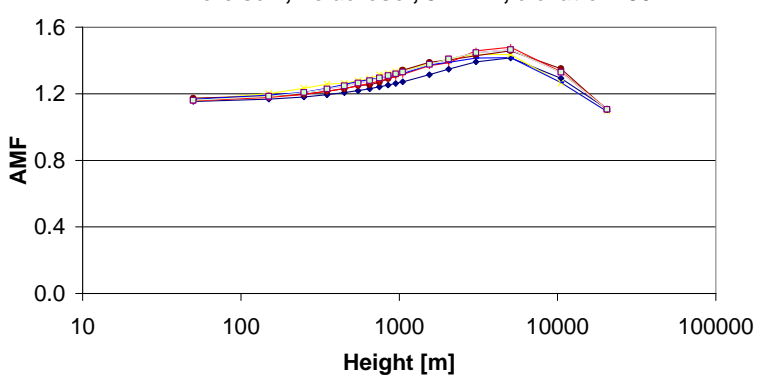

AMF Exercise 1, A2, $577 \mathrm{~nm}$, elevation: $1^{\circ}$

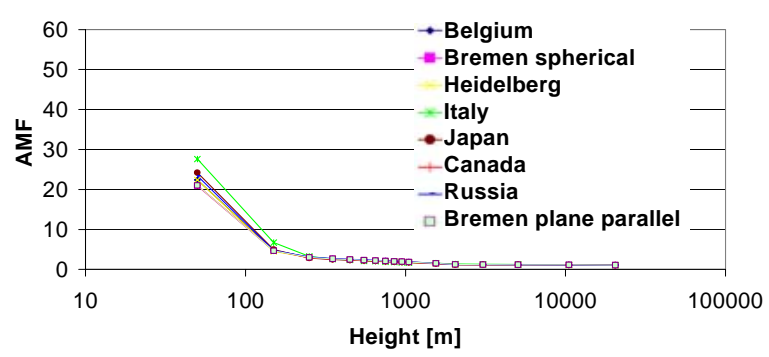

AMF Exercise 1, A2, $577 \mathrm{~nm}$, elevation: $3^{\circ}$

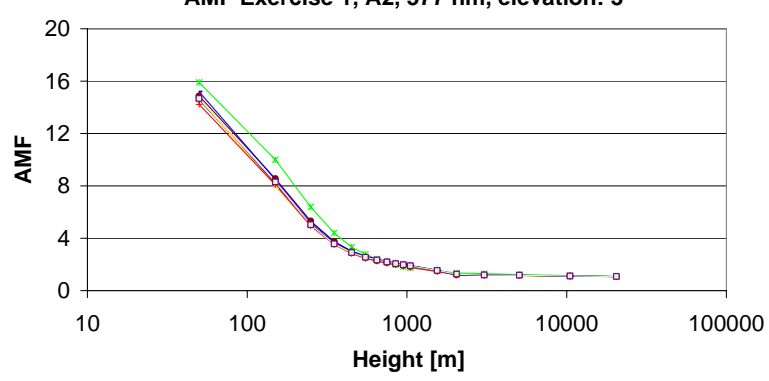

AMF Exercise 1, A2, $577 \mathrm{~nm}$, elevation: $6^{\circ}$

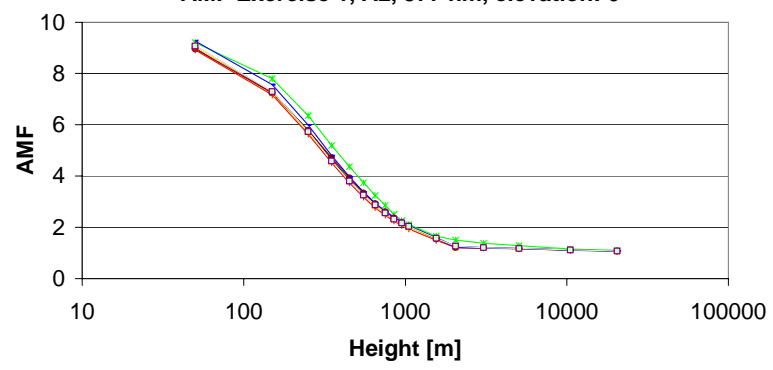

AMF Exercise 1, A2, $577 \mathrm{~nm}$, elevation: $20^{\circ}$

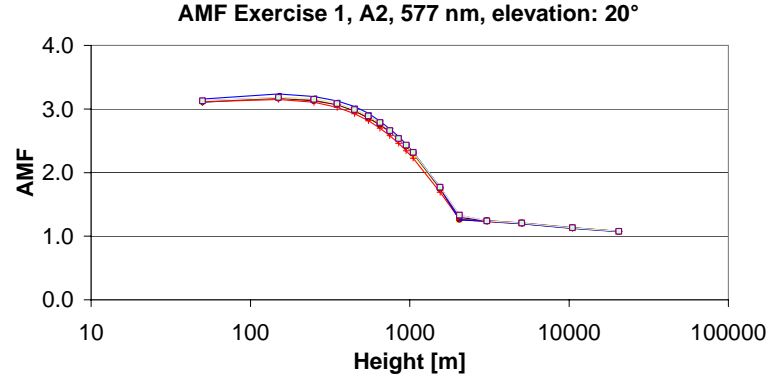

AMF Exercise 1, A2, $577 \mathrm{~nm}$, elevation: $90^{\circ}$

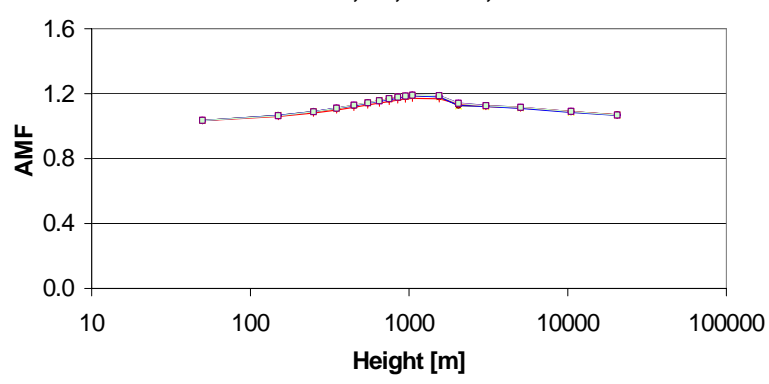

Fig. 5. Box-AMFs for $577 \mathrm{~nm}$ as a function of altitude (logarithmic scale). Left: pure Rayleigh-atmosphere. Right: including aerosol scattering (scenario A2, see Table 4). From top to bottom the elevation angle increases from $1^{\circ}$ to $90^{\circ}$. 

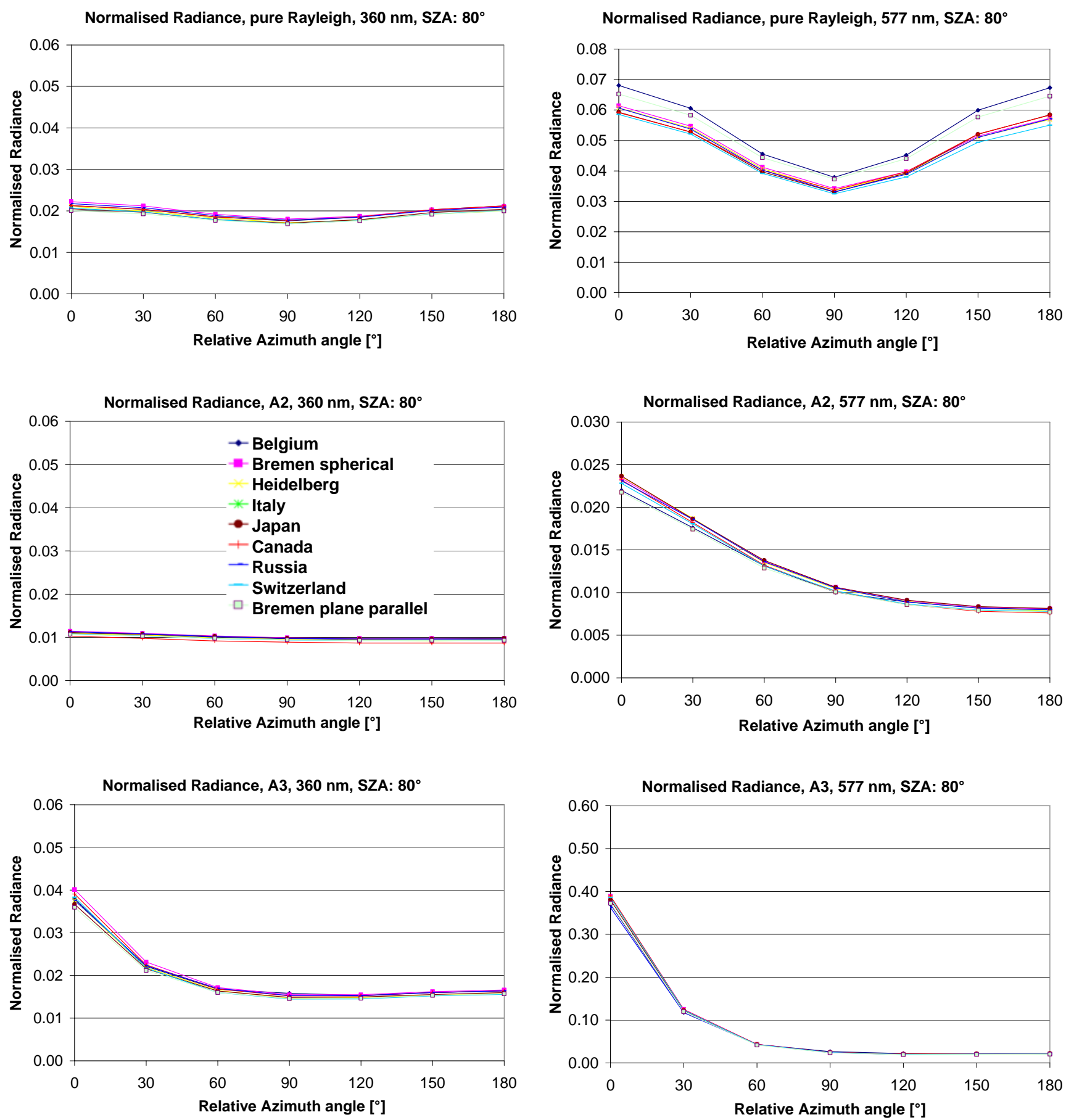

Fig. 6. Normalised radiances as a function of the relative azimuth angle for $360 \mathrm{~nm}$ (left) and $577 \mathrm{~nm}$ (right). Results are for a pure Rayleigh atmosphere (top) and for the two aerosol scenarios A2 (centre) and A3 (bottom), see Table 4. Please note that for $577 \mathrm{~nm}$ different y-scales are used.

the telescope is directly proportional to the phase function of the scattering process. For Rayleigh-scattering the phase function has a symmetric maximum in forward and backward direction causing a maximum in the observed normalised radiance for relative azimuth angles of $0^{\circ}$ and $180^{\circ}$; for a rel- ative azimuth angle of $90^{\circ}$ (and $270^{\circ}$ ) a minimum occurs For scattering on aerosols, the phase function typically has a pronounced maximum in forward direction. Thus, the observed normalised radiance for a relative azimuth angle of $0^{\circ}$ is much larger than for $180^{\circ}$. 
In contrast to the single scattered photons (or those with only few scattering events), the contribution of multiple scattered photons depends only weakly on the relative azimuth angle. Thus, the strength of the azimuth dependence of the normalised radiance (and also of the box-AMF) decreases for an increasing fraction of multiple scattered photons (for example, inside a dense cloud, the normalised radiance does not depend on the viewing direction anymore). Therefore, it is possible to derive additional information on the atmospheric aerosol load from the azimuth dependence of the measured normalised radiance and $\mathrm{O}_{2}$ and $\mathrm{O}_{4}$ absorption (Wagner et al., 2004; Frieß et al., 2006).

In this exercise, normalised radiances and box-AMFs were modelled for 7 relative azimuth angles $\left(0^{\circ}, 30^{\circ}, 60^{\circ}, 90^{\circ}\right.$, $\left.120^{\circ}, 150^{\circ}, 180^{\circ}\right)$. The elevation angle was set to $2^{\circ}$ and the solar zenith angle was set to $80^{\circ}$ ensuring that the different relative azimuth angles relate to a representative range of the scattering phase functions for single scattered photons. The model runs are performed for a pure Rayleigh atmosphere and for two aerosol scenarios (see Table 4). In Fig. 6 the modelled normalised radiances are shown as a function of the relative azimuth angle. For the pure Rayleigh atmosphere, the normalised radiances show the expected maxima at $0^{\circ}$ and $180^{\circ}$ and a minimum at $90^{\circ}$. For $577 \mathrm{~nm}$ the minimum is more pronounced because of the smaller contribution of multiple scattered photons. As for the previous exercise, the deviations between the different models are largest for $577 \mathrm{~nm}$ and a pure Rayleigh atmosphere. Again, the highest normalised radiances are found for the models using plane parallel geometry. If also aerosol scattering occurs, the normalised radiances in forward direction become systematically larger than in backward direction caused by the pronounced forward maximum of the aerosol phase function. The results for the two aerosol scenarios demonstrate that depending on the optical depth and the viewing direction, aerosol scattering can both increase and decrease the observed normalised radiance. For weak and moderate optical depths (e.g. scenario A3), the main effect is that aerosol scattering increases the probability of additional photons being scattered into the telescope along the line of sight. Consequently, increased normalised radiances are modelled (Fig. 6, bottom). For larger optical depths (e.g. scenario A2), the additional extinction along the line of sight (over-) compensates this increase and the observed normalised radiances can become even smaller than for the pure Rayleigh atmosphere (Fig. 6, centre).

It is interesting to note that the strongest differences of the normalised radiance between forward and backward direction is found for cases with weak or moderate aerosol optical depth (e.g. scenario A3) and for small optical depth with respect to Rayleigh-scattering (e.g. $577 \mathrm{~nm}$ ). For these cases, the relative fraction of photons which have encountered single scattering on aerosols is largest; thus the asymmetry of the aerosol phase function has the strongest effect on the modelled normalised radiances.
Figures 7 and 8 show the box-AMFs for $360 \mathrm{~nm}$ and $577 \mathrm{~nm}$ as a function of altitude. The different graphs show the results for different relative azimuth angles and aerosol scenarios (including a pure Rayleigh atmosphere). For most cases, a similar dependence on altitude as for the first exercise is found: the highest box-AMFs (about $1 / \cos \left(2^{\circ}\right) \approx 28$ ) are found for the lowest atmospheric layers; with increasing altitude they decrease to values close to the geometrical approximation for a solar zenith angle of $80^{\circ}\left(1 / \cos \left(80^{\circ}\right) \approx 5.8\right)$.

For the scenario with strong aerosol extinction (scenario A2, see Table 4), the box-AMFs show minimum values within the aerosol layer. This indicates that this layer is characterised by a high fraction of multiply scattered photons. The effective light paths of the diffuse radiation in these layers are smaller than the light paths in the layers below and above, which are determined by the slant line of sight and slant direct solar beam. Another interesting feature is that at $577 \mathrm{~nm}$ the box-AMFs for the moderate aerosol extinction (scenario A3) show large differences between forward and backward direction (Fig. 8). Especially for the layer around $1 \mathrm{~km}$ altitude, the box-AMF varies by about a factor of 2 (see also Fig. 9). This is caused by the different probability of photons to be (single-) scattered from the incoming solar beam into the line of sight of the telescope. In forward direction, many photons are scattered close to the surface, having penetrated the atmospheric layer at $1 \mathrm{~km}$ in the direction of the incoming solar beam and the AMF is about $1 / \cos \left(80^{\circ}\right) \approx 5.8$. In contrast, the probability of backward aerosol scattering is much smaller and thus more photons have been scattered into the line of sight from higher altitudes. They have penetrated the atmospheric layer at $1 \mathrm{~km}$ in the direction of the line of sight of the telescope, for which the AMF is much larger.

It is interesting to note that this strong asymmetry is not observed for the box-AMFs at $360 \mathrm{~nm}$ (Fig. 9). For this wavelength the optical depth for Rayleigh-scattering is much larger and consequently, most photons are scattered close to the surface, irrespective of the relative azimuth angle.

In summary, we can again state that good agreement (differences $<5 \%$ ) is found for most of the cases. However, as for the previous exercise, systematic differences between spherical and plane-parallel models occur for the exercise with a pure Rayleigh-atmosphere at $577 \mathrm{~nm}$, for which the path length along the line of sight and the atmospheric path of the slant direct solar beam become very long.

It is interesting to note that not only the normalised radiance, but also the box-AMFs for particular aerosol scenarios become strongly dependent on the relative azimuth angle. Thus MAX-DOAS observations of $\mathrm{O}_{2}$ and $\mathrm{O}_{4}$ at different azimuth angles can provide information on the atmospheric aerosol load (see e.g. Wagner et al., 2004; Wittrock et al., 2004, and references in the publication list given in Sect. 1.2). 
AMF, pure Rayleigh, $360 \mathrm{~nm}, 0^{\circ}$ azim., $2^{\circ}$ elev., $80^{\circ} \mathrm{SZA}$

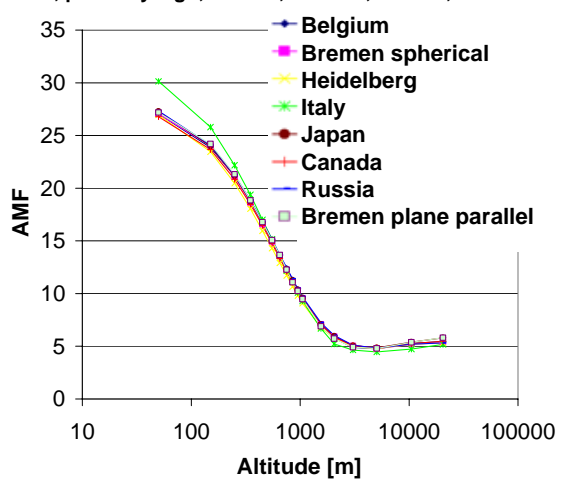

AMF, pure Rayleigh, $360 \mathrm{~nm}, 90^{\circ}$ azim., $2^{\circ}$ elev., $80^{\circ} \mathrm{SZA}$

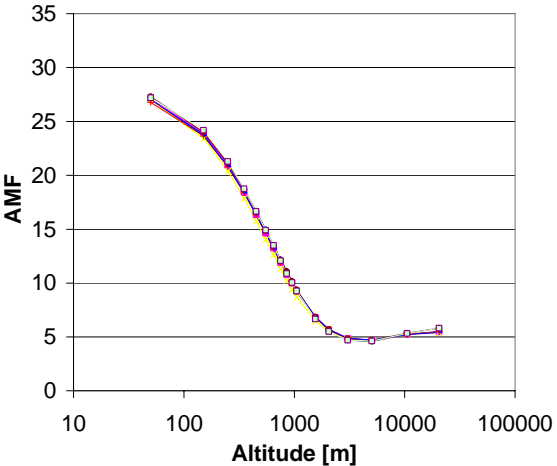

AMF, pure Rayleigh, $360 \mathrm{~nm}, 180^{\circ}$ azim., $2^{\circ}$ elev., $80^{\circ} \mathrm{SZA}$

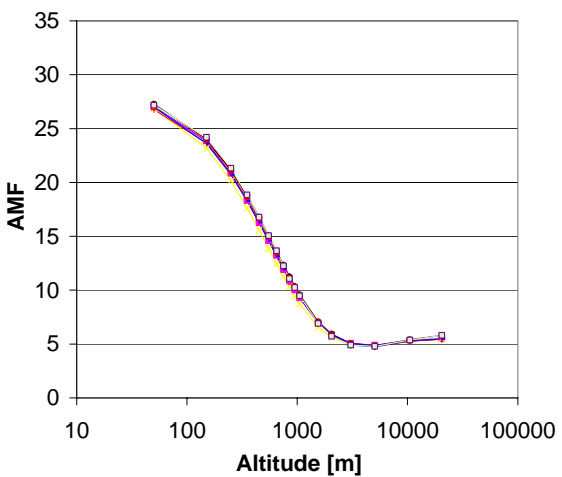

AMF, A2, $360 \mathrm{~nm}, 0^{\circ}$ azim., $2^{\circ}$ elev., $80^{\circ} \mathrm{SZA}$

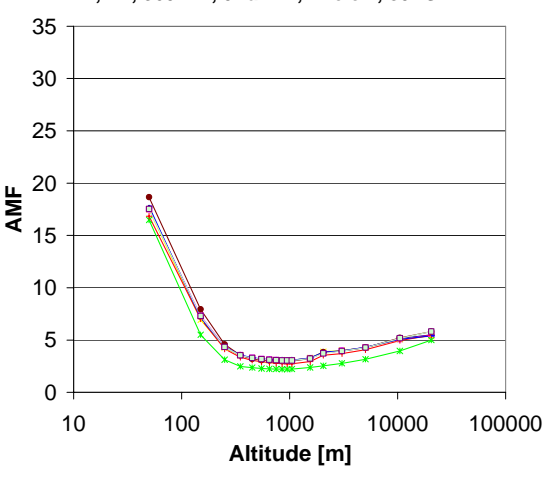

AMF, A2, $360 \mathrm{~nm}, 90^{\circ}$ azim., $2^{\circ}$ elev., $80^{\circ} \mathrm{SZA}$

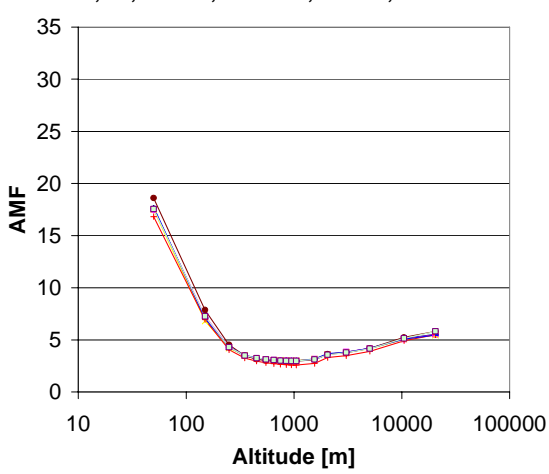

AMF, A2, $360 \mathrm{~nm}, 180^{\circ}$ azim., $2^{\circ}$ elev., $80^{\circ} \mathrm{SZA}$

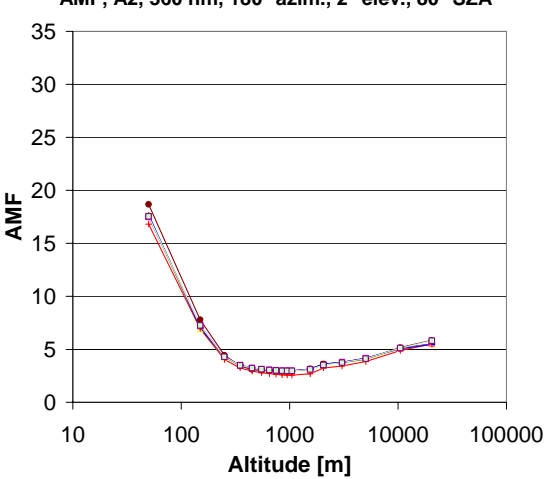

AMF, A3, $360 \mathrm{~nm}, 0^{\circ}$ azim., $2^{\circ}$ elev, $80^{\circ} \mathrm{SZA}$

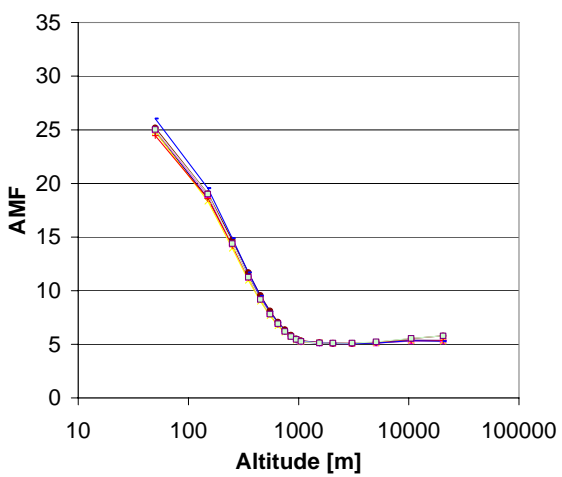

AMF, $\mathrm{A} 3,360 \mathrm{~nm}, 90^{\circ}$ azim., $2^{\circ}$ elev., $80^{\circ} \mathrm{SZA}$
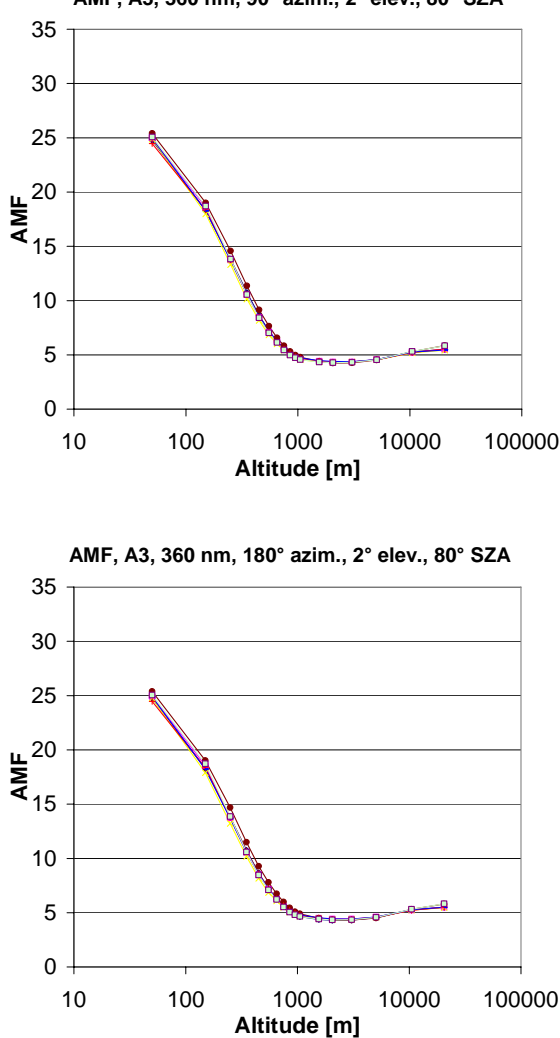

Fig. 7. Box-AMFs for $360 \mathrm{~nm}$, an elevation angle of $2^{\circ}$ and a SZA of $80^{\circ}$ as a function of altitude (logarithmic scale) for different relative azimuth angles (top: $0^{\circ}$, centre: $90^{\circ}$, bottom: $180^{\circ}$ ). The calculations were performed for different aerosol scenarios (left: no aerosols, centre: scenario A2, right: scenario A3, see Table 4).

\subsection{The influence of Earth's sphericity}

As already discussed in the previous sections, the treatment of the Earth's sphericity can have a strong influence on the modelled normalised radiances and box-AMFs. This influence becomes particularly large, if the photons traverse the atmosphere on extended slant paths, which can appear for small elevation angles, and/or for large solar zenith angles. The effect of the treatment of the Earth's sphericity can be well demonstrated by models, which are operated in both spherical and plane parallel modes. In Figs. 10 and 11, examples from the Japanese model for $577 \mathrm{~nm}$ and a pure Rayleigh atmosphere are shown. Especially for small elevation angles substantial differences in the modelled radiances (about $>15 \%$ for elevation angles below $3^{\circ}$ ) and box-AMFs are found (up to a factor of two for high altitudes). These results confirm the findings from Sect. 4.1 (Figs. 3 and 5). 
AMF, pure Rayleigh, $577 \mathrm{~nm}, 0^{\circ}$ azim., $2^{\circ}$ elev., $80^{\circ} \mathrm{SZA}$

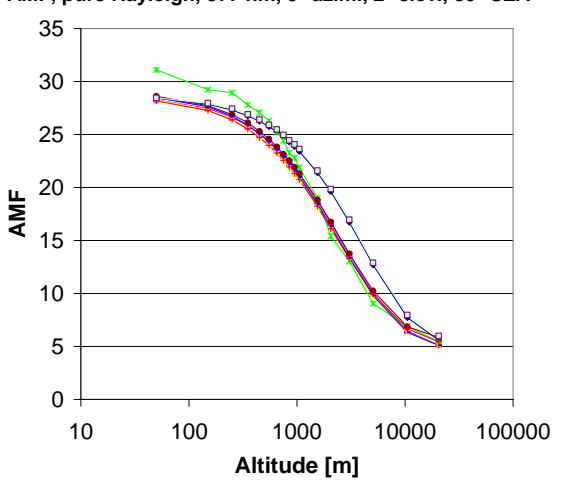

AMF, pure Rayleigh, $577 \mathrm{~nm}, 90^{\circ}$ azim., $2^{\circ}$ elev., $80^{\circ} \mathrm{SZA}$

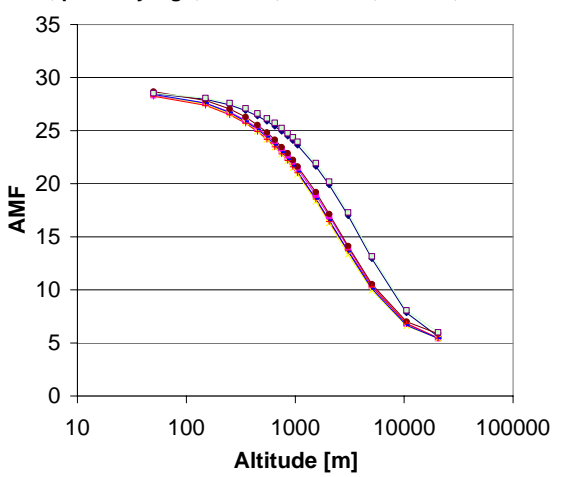

AMF, pure Rayleigh, $577 \mathrm{~nm}, 180^{\circ}$ azim., $2^{\circ}$ elev., $80^{\circ} \mathrm{SZA}$

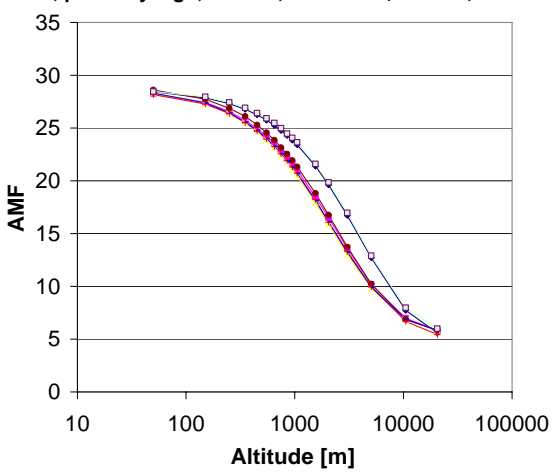

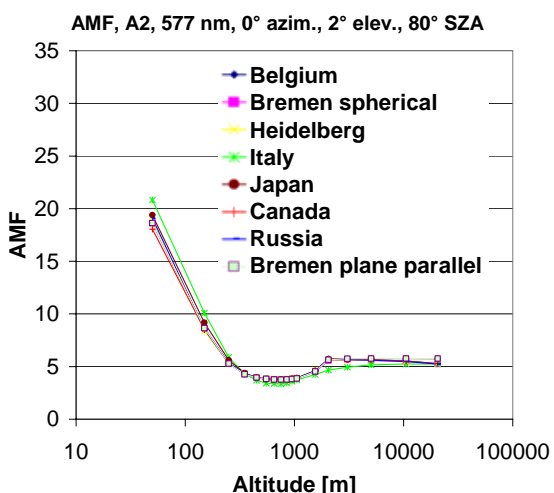

AMF, A3, $577 \mathrm{~nm}, 0^{\circ}$ azim., $2^{\circ}$ elev., $80^{\circ} \mathrm{SZA}$
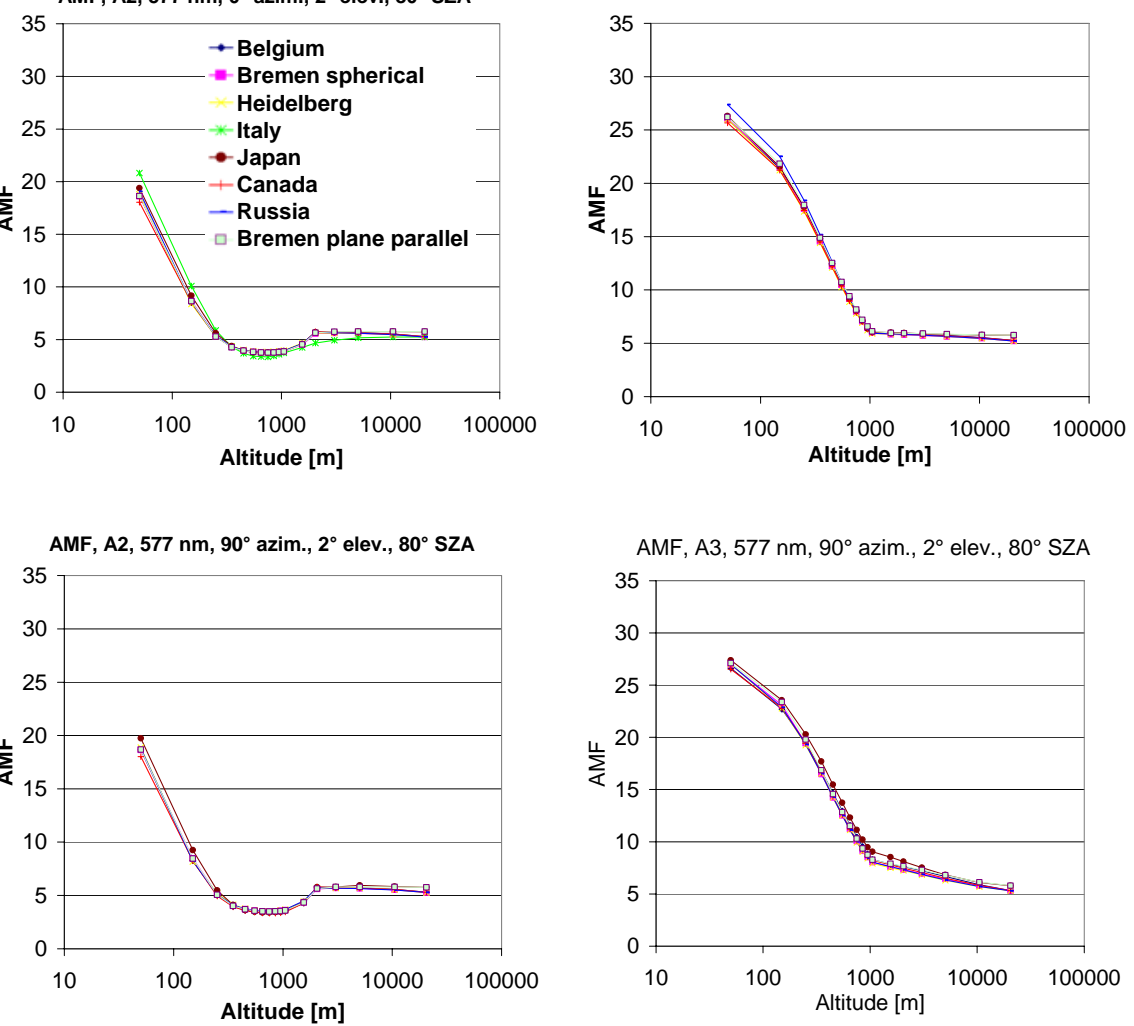

AMF, A2, $577 \mathrm{~nm}, 180^{\circ}$ azim., $2^{\circ}$ elev., $80^{\circ} \mathrm{SZA}$

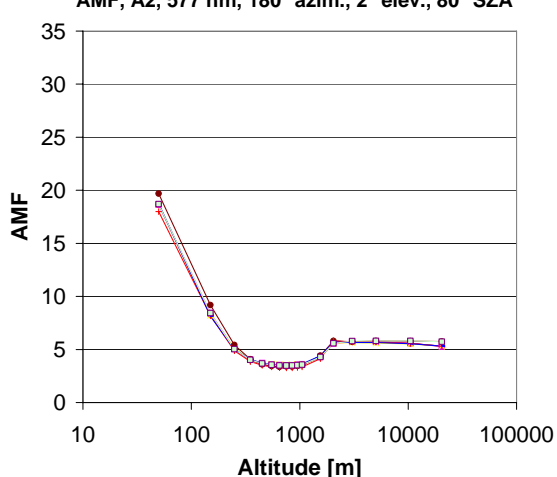

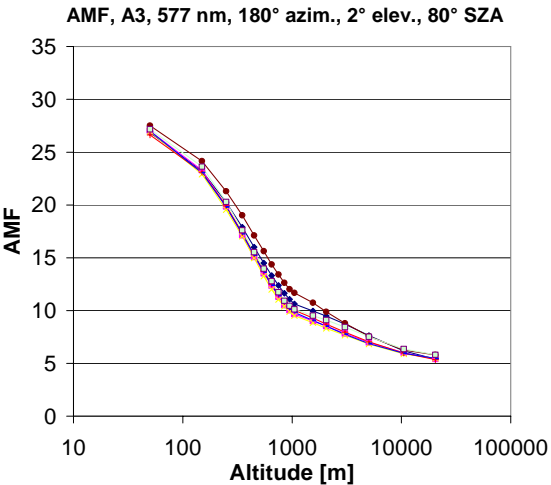

Fig. 8. Box-AMFs for $577 \mathrm{~nm}$, an elevation angle of $2^{\circ}$ and a SZA of $80^{\circ}$ as a function of altitude (logarithmic scale) for different relative azimuth angles (top: $0^{\circ}$, centre: $90^{\circ}$, bottom: $180^{\circ}$ ). The calculations were performed for different aerosol scenarios (left: no aerosols, centre: scenario A2, right: scenario A3, see Table 4).

It thus becomes obvious that for scenarios with small optical depth with respect to aerosol and Rayleigh-scattering, the correct treatment of the Earth's sphericity is a prerequisite for correct results. It can also be seen in Figs. 10 and 11 that the influence of refraction is relatively small.

\subsection{The influence of ground albedo}

If a substantial part of the observed photons was scattered more than once between the sun and the instrument, re- flection (or scattering) on the Earth's surface becomes important. If the ground albedo is low, most photons which have hit the surface are absorbed and don't contribute to the measured normalised radiance. In contrast, if the ground albedo is high, reflection on the surface can strongly enhance the observed normalised radiance. Also the effective photon path lengths (and thus the box-AMFs) can be substantially increased. Since photons close to the surface have the largest probability to hit the ground, the strongest effect of the ground albedo on the box-AMFs can be expected for the 

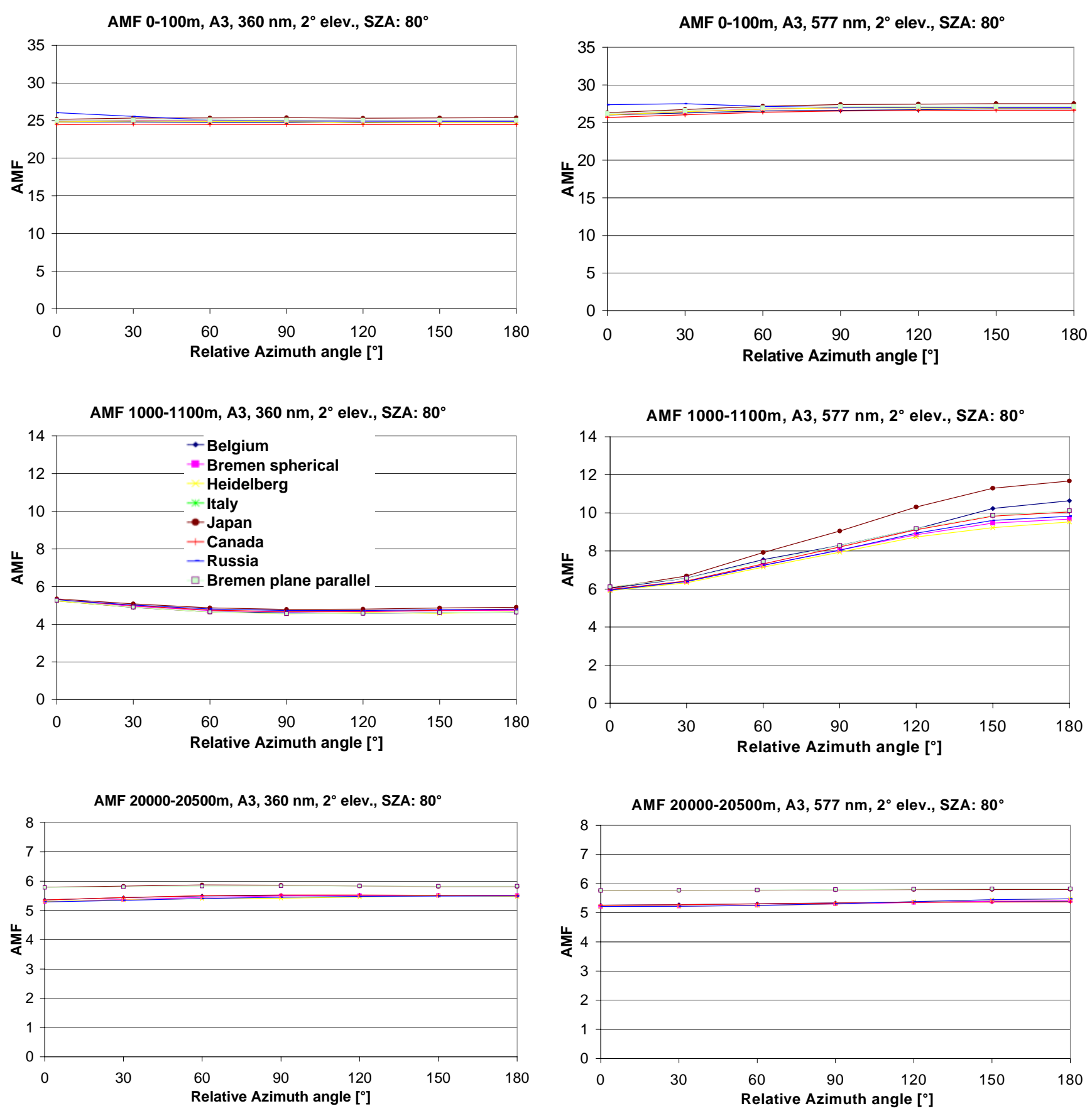

Fig. 9. Azimuth dependence for the box-AMFs at different altitudes for moderate aerosol scattering (scenario A3, see Table 4). At 577 nm the AMFs for layers in the free troposphere are much larger for the backward direction than for the forward direction; the strongest azimuth dependence is found for an altitude of $1 \mathrm{~km}$. The box-AMFs for low and high altitudes show almost no azimuth dependence. For $360 \mathrm{~nm}$ almost no dependence is found.

surface near layers. Thus the effect is especially important for MAX-DOAS observations.

In Fig. 12 the modelled normalised radiances are shown for the scenarios as in Sect. 4.2 but for a ground albedo of $80 \%$ (instead of $3 \%$ ). Such high ground albedo can oc- cur over fresh snow. Compared to Fig. 6 where the normalised radiances for the same scenarios but with $3 \%$ ground albedo are shown, the values are systematically higher. The strongest relative increase is found for $360 \mathrm{~nm}$, where the fraction of multiple scattered photons is particularly high. 
Exercise 1, pure Rayleigh, 577nm, SZA: $20^{\circ}$

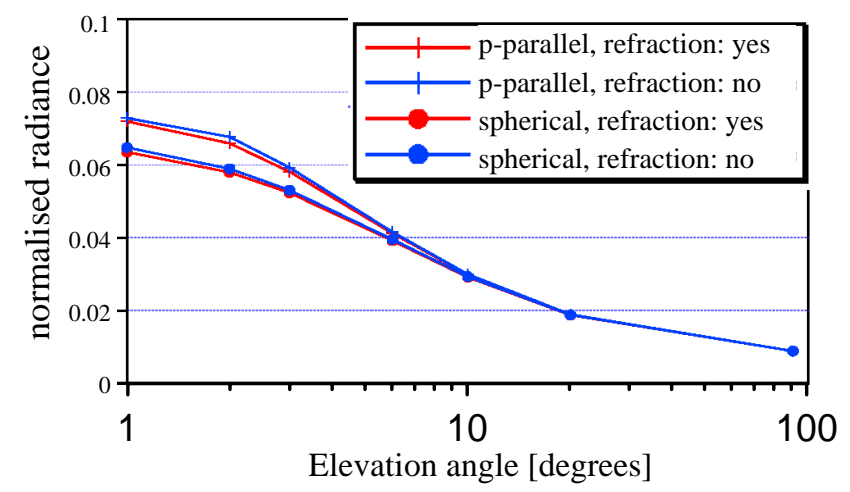

Fig. 10. Normalised radiances calculated by the Japanese model for various elevation angles (for a pure Rayleigh atmosphere, solar zenith angle of $20^{\circ}$, relative azimuth angle of $0^{\circ}$, and wavelength of $577 \mathrm{~nm})$. If the Earth's sphericity is not taken into account, substantial systematic errors can occur ( $<15 \%$ for small elevation angles). In contrast, refraction has only small influence.

For low aerosol optical depth, the relative increase is only moderate. This can be explained by the pronounced forward peak of the scattering phase function for aerosols. The probability of photons which have hit the ground to be scattered into the line of sight of the telescope through aerosol scattering is much smaller than for Rayleigh-scattering.

Figure 13 shows box-AMFs for selected scenarios of Sect. 4.2, but for a ground albedo of $80 \%$ (instead of 3\%). For the pure Rayleigh atmosphere, the box-AMFs for the lowest atmospheric layers are significantly increased, as expected because of the increased path lengths of the photons reflected on the ground.

If aerosols are present, the increase of the box-AMFs becomes dependent on the relative azimuth angle. For a relative azimuth angle of $0^{\circ}$ a large fraction of the observed photons is scattered on aerosols because of the strong forward peak of the phase function. Thus ground reflection plays only a limited role. In contrast, for relative azimuth angles of $90^{\circ}$ and $180^{\circ}$, aerosol scattering has a smaller impact on the light path. In these cases, for photons having hit the ground, the probability to be scattered into the line of sight of the telescope is much higher than for aerosol scattering. Thus the box-AMFs for the lowest atmospheric layers are substantially enhanced compared to the results for low ground albedo. Please note that for this exercise, not all participating groups have provided data.

\subsection{Influence of the asymmetry parameter}

We also investigated the influence of a modified asymmetry parameter, i.e. a changed aerosol scattering phase function. Instead of 0.68 as for the previous exercises, we used a value of 0.75 . This increased value causes a stronger forward peak
Exercise 1, pure Rayleigh, $577 \mathrm{~nm}$, SZA: $20^{\circ}$, elevation: $10^{\circ}$

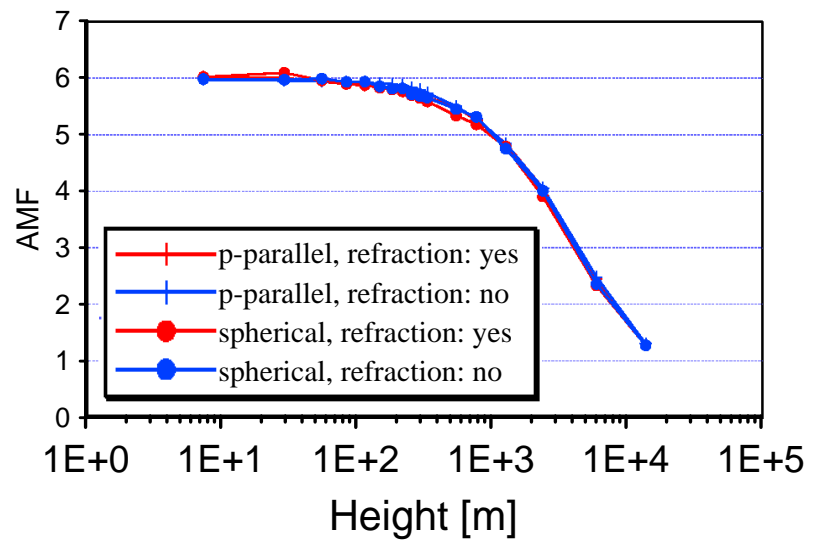

Exercise 1, pure Rayleigh, 577nm, SZA: $20^{\circ}$, elevation: $1^{\circ}$

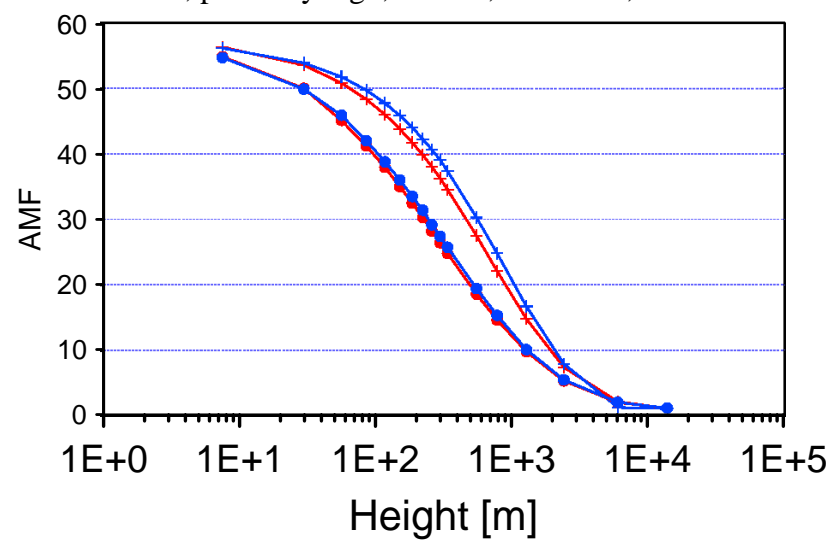

Fig. 11. Box-AMFs calculated by the Japanese model for an elevation angle of $10^{\circ}$ (left) and $1^{\circ}$ (right) for a pure Rayleigh atmosphere (solar zenith angle: $20^{\circ}$, relative azimuth angle: $0^{\circ}$, wavelength: $577 \mathrm{~nm}$ ). If the Earth's sphericity is not taken into account, large errors can occur (up to a factor of two). In contrast, refraction has only a relatively small influence on the box-AMFs.

of the scattering phase function (representing smaller particle sizes).

In Fig. 14 the modelled normalised radiances are shown for selected scenarios from Sect. 4.2, but with the asymmetry parameter of 0.75 . The enhanced forward peak of the aerosol phase function now causes systematically enhanced normalised radiances for a relative azimuth angle of $0^{\circ}$. The normalised radiances for other relative azimuth angles, however, are almost unchanged. Also the box-AMFs (not shown) are almost identical to the results for an asymmetry parameter of 0.68 . Please note that for this exercise, not all participating groups have provided data.

\section{Conclusions}

An extended comparison exercise of nine radiative transfer models (from eight international research groups) for the UV 
Normalised Radiance, pure Rayleigh, $360 \mathrm{~nm}, \mathrm{SZA}: 80^{\circ}$
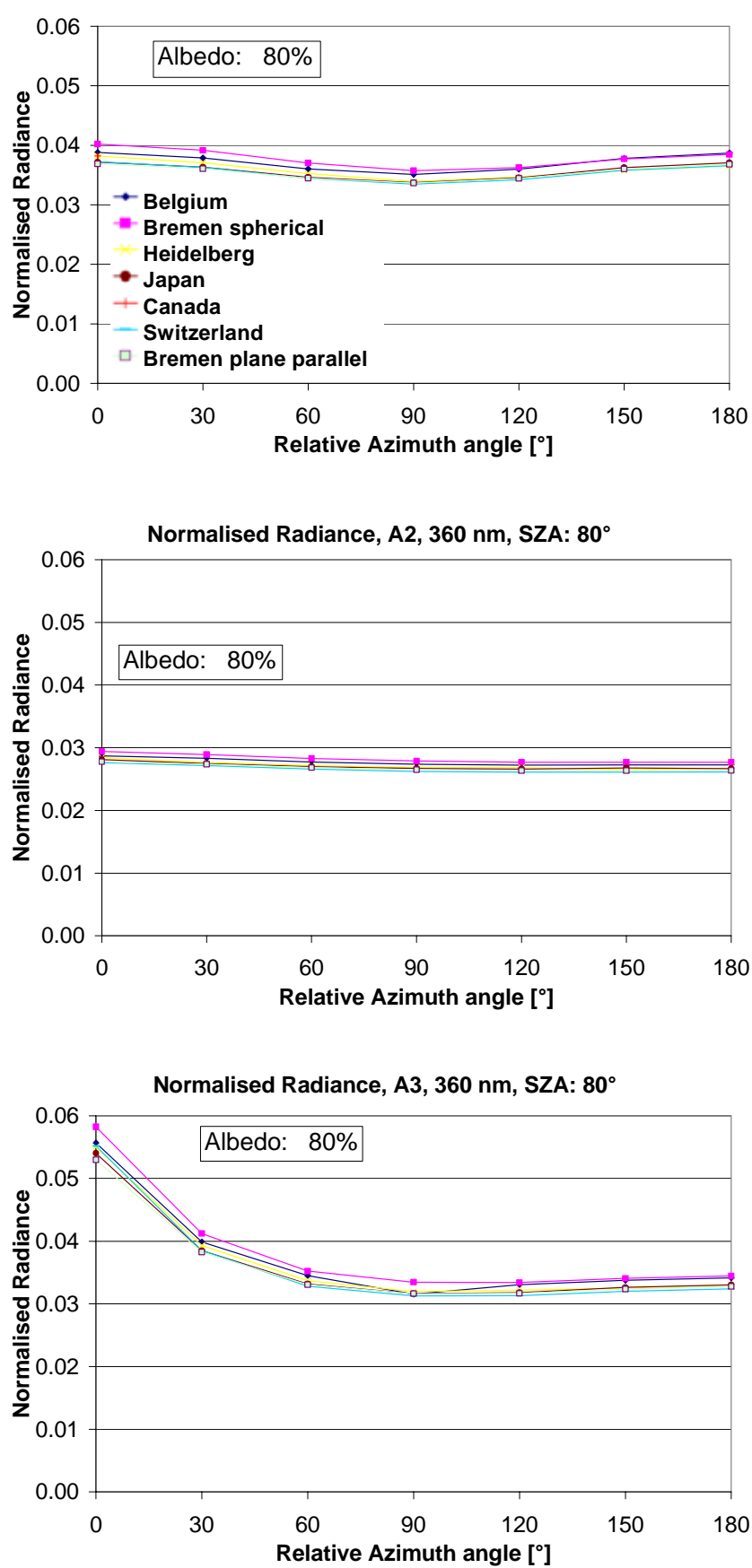

Normalised Radiance, pure Rayleigh, $577 \mathrm{~nm}$, SZA: $80^{\circ}$

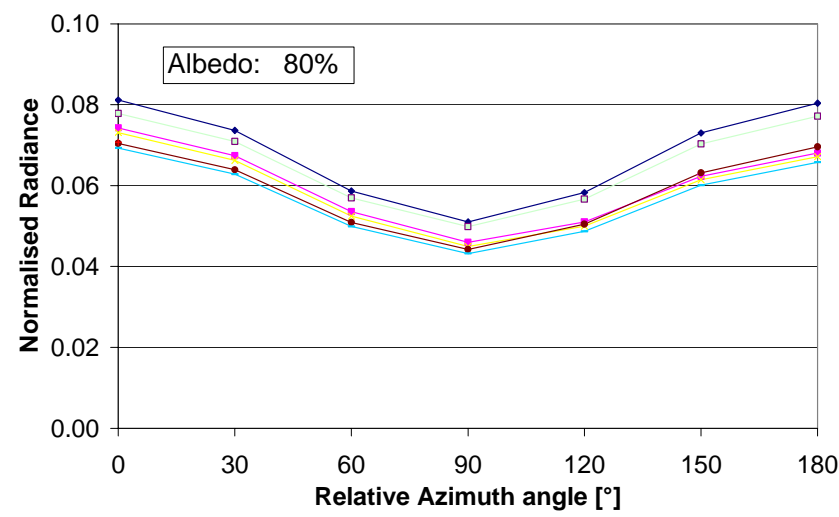

Normalised Radiance, A2, $577 \mathrm{~nm}, \mathrm{SZA}: 80^{\circ}$

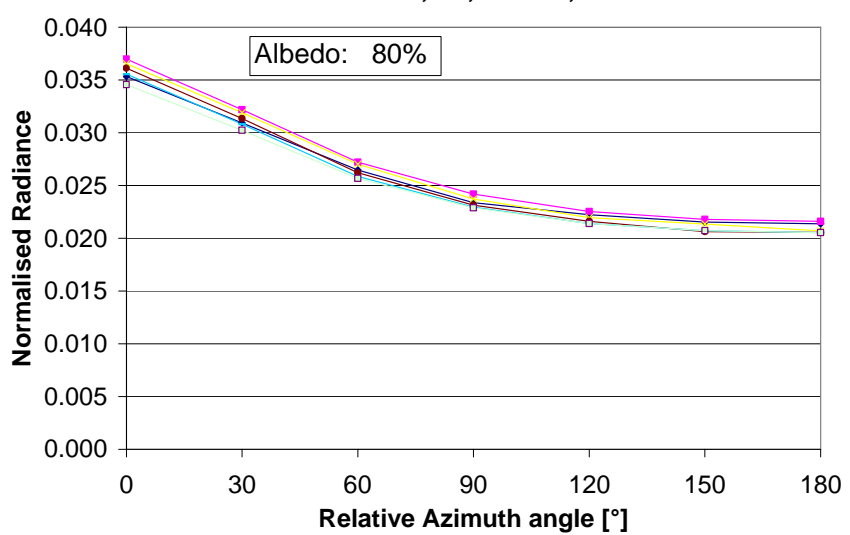

Normalised Radiance, A3, $577 \mathrm{~nm}, \mathrm{SZA}: 80^{\circ}$

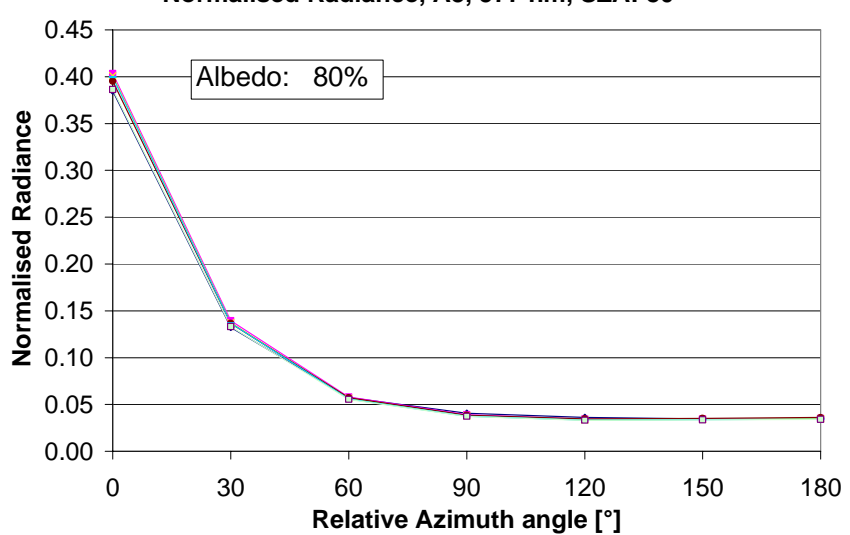

Fig. 12. Normalised radiances as a function of the relative azimuth angle for $360 \mathrm{~nm}$ (left) and $577 \mathrm{~nm}$ (right). Results are for a pure Rayleigh atmosphere (top) and for the two aerosol scenarios A2 (centre) and A3 (bottom), see Table 4. The model scenarios are identical to Fig. 6, but for a ground albedo of $80 \%$ (instead of $3 \%$ ). Please note that for $577 \mathrm{~nm}$ different $\mathrm{y}$-scales are used.

and visible spectral range was performed. The main purpose of the participating models is to simulate remote sensing observations from various platforms. The comparison exercise focused on the recently developed MAX-DOAS method, which is particularly sensitive to tropospheric trace gases. Besides the assessment of the agreement between the differ- ent models, a second focus of the comparison was the systematic investigation of the sensitivity of the MAX-DOAS technique under various viewing geometries and aerosol conditions (pure Rayleigh atmosphere or varying aerosol loads, see Table 4). 

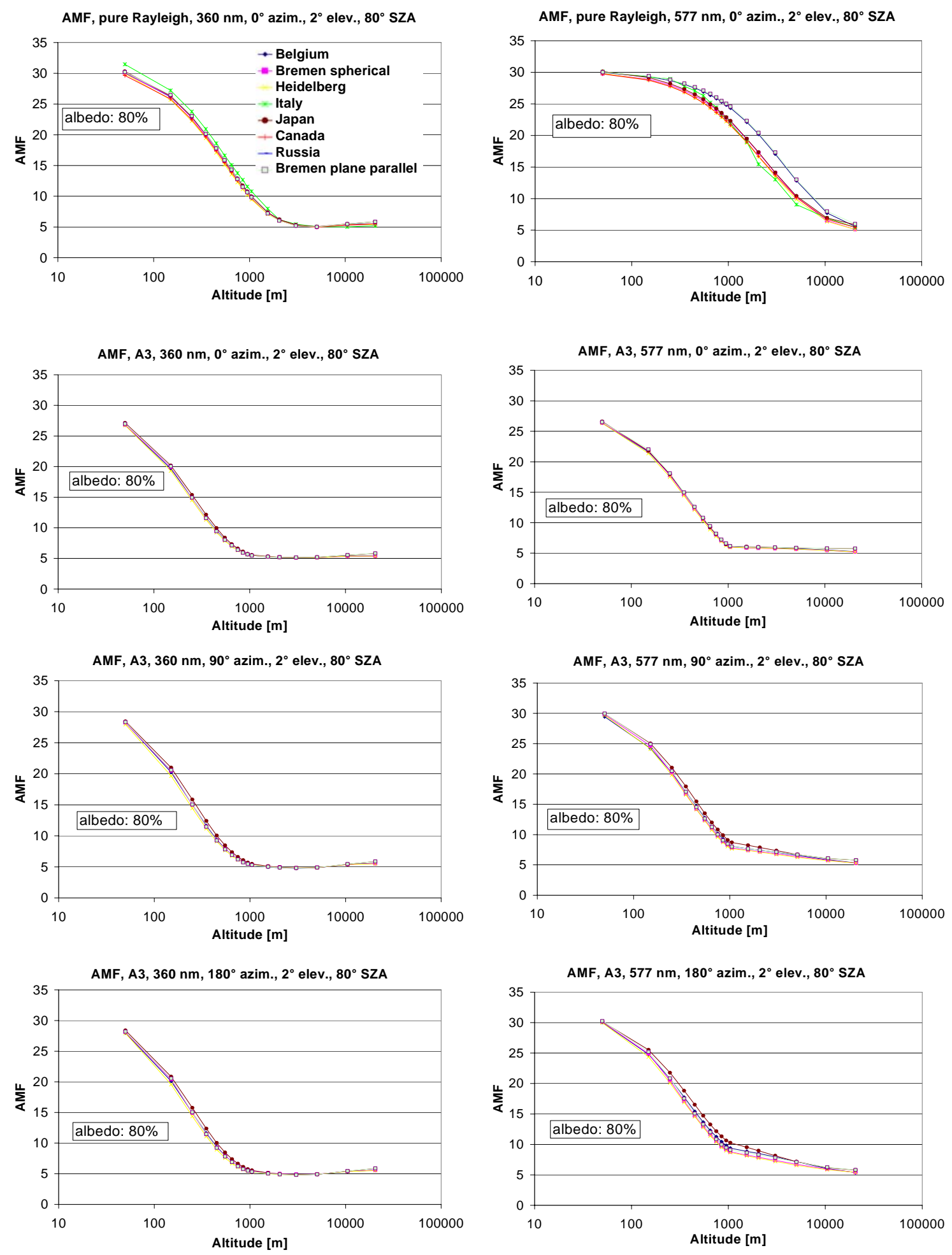

Fig. 13. Box-AMFs for $360 \mathrm{~nm}$ (left) and $577 \mathrm{~nm}$ (right) as a function of altitude (logarithmic scale) for different relative azimuth angles and without (top) or with aerosols (centre and bottom). The results are obtained for a ground albedo of $80 \%$ (compared to $3 \%$ as shown in Figs. 7 and 8). The enhanced albedo leads to slightly higher box-AMFs for the surface near layers (except for the aerosol scenario with relative azimuth angle of $0^{\circ}$ ). 

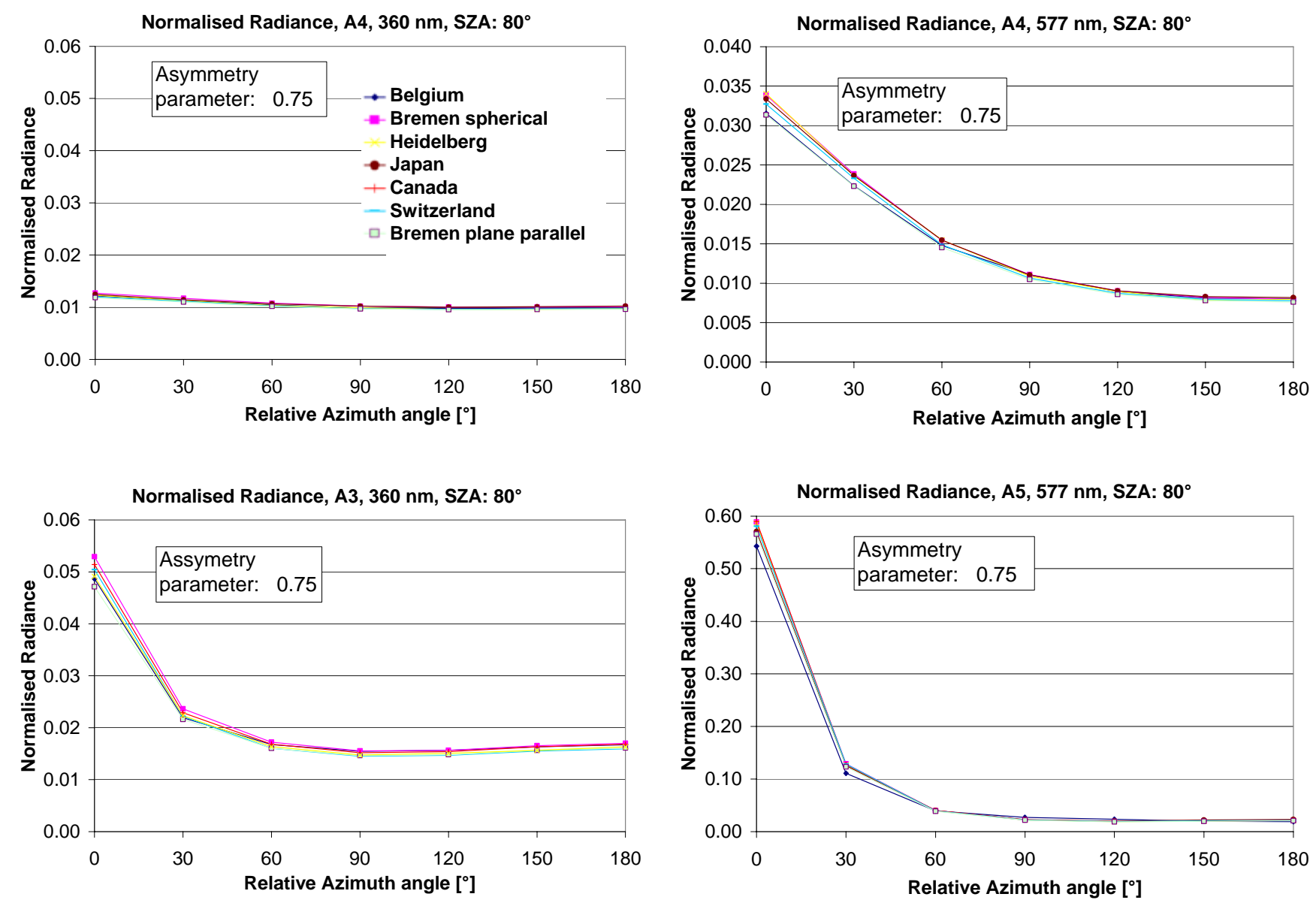

Fig. 14. Normalised radiances as a function of altitude (logarithmic scale) for different relative azimuth angles for $360 \mathrm{~nm}$ (left) and $577 \mathrm{~nm}$ (right). Results are as for Fig. 6, but now for an asymmetry parameter of 0.75 (instead of 0.68). Please note that for $577 \mathrm{~nm}$ different $\mathrm{y}$-scales are used.

In contrast to previous comparison exercises, not only air mass factors were modelled, but also (normalised) radiances. The comparison of radiances proved to be particularly useful to discover errors, which might have been overlooked if only AMFs were compared. Accurate modelling of radiances is also a prerequisite for the correct interpretation of satellite observations, for which the measured radiance can strongly vary across large ground pixels. It is interesting to note here that in the final version of the comparison exercise, the differences found for the modelled radiances are of similar magnitude as those of the box-AMFs while at the beginning of the comparison the deviations of the radiances were by far larger.

Another new aspect of this exercise is the calculation of box-AMFs for various atmospheric layers. Such box-AMFs (similar to weighting functions) characterise the sensitivity of the MAX-DOAS observations as a function of altitude.

The comparison exercise was divided into two major parts. In the first part, the dependence on the elevation angle and in the second part, the dependence on the relative azimuth angle between the directions of the telescope and the sun was investigated. For both parts, a very good overall agreement (differences $<5 \%$ ) for the radiances and the box-AMFs of the various RTMs was found (one exception is the Italian model, for which systematic differences from the other models occur especially for large elevation angles. The reason for this finding is still under investigation). It should be noted that the differences between the models might be further reduced if fixed discretisation schemes (e.g. for the vertical layering and the scattering angles) were used. Especially close to the ground, the vertical discretisation has to be chosen fine enough $(\leq 100 \mathrm{~m})$; otherwise, the strong gradients close to the surface could not be treated correctly, and interpolation errors can lead to substantial errors. In addition, it was found that for low atmospheric optical depth (low aerosol load and large wavelength) and small elevation angles, the correct treatment of the Earth's sphericity becomes indispensable (while the effect of atmospheric refraction is typically negligible). 
From both parts of the exercise it became obvious that MAX-DOAS observations are indeed very sensitive to the lowest atmospheric layers. Depending on the atmospheric conditions and on wavelength, the box-AMFs for the nearsurface layers can reach very high values $(>50)$. The results also indicated that additional scattering by aerosols strongly modifies the atmospheric radiative transfer. Aerosols increase the optical depth (enhance the probability of scattering) and also lead to an asymmetry in the scattering direction because of the pronounced forward peak of the aerosol phase function. The influence of additional aerosol scattering not only affects the dependence of the radiance and box-AMFs on the elevation angle but also on the relative azimuth angle (Wagner et al., 2004; Frieß et al., 2006).

Within two additional sensitivity studies, the influence of a modified ground albedo and aerosol phase function was investigated. Especially for the lowest atmospheric layers, a high ground albedo strongly enhances the observed radiance and the box-AMFs. In contrast, for the considered cases the change in aerosol phase function has a rather small effect.

During the various iterations of the comparison exercise substantial progress was made. The comparison of the first results had exhibited large differences between the models, both for the modelled radiances and box-AMFs. Many errors were caused by simple mistakes and could be easily corrected. As during the following iterations the agreement became better, also more subtle errors could be identified and corrected. In this way, the RTM comparison exercise caused a consolidation of currently applied RTMs.

The settings of this RTM comparison exercise are available (together with additional results and a detailed documentation) via the following web-site: http://satellite.iup. uni-heidelberg.de/index.php/RTM_Workshop. The simulated box-AMFs constitute a universal data base for the interpretation of arbitrary MAX-DOAS applications (arbitrary total AMFs can be derived by simple convolution with a given trace gas concentration profile). Together with the modelled radiances and the specified settings for the various exercises, they can serve as test cases for future RTM developments.

Acknowledgements. We want to express two special thanks to K. Kreher and G. Bodeker (NIWA, New Zealand) for the initiative for this workshop and their leading role in setting up the exercise specifications. Part of the workshop was sponsored by the ACCENT project. Work performed by H. Irie and Y. Kanaya at FRCGC/JAMSTEC was supported by Global Environment Research fund (B-051). Work performed by O. Postylyakov was supported by the Russian Foundation for Basic Research for support (grant 05-05-65139).

Edited by: R. Volkamer

\section{References}

Acharya, P. K., Berk, A., Anderson, G. P., Larsen, N. F., Tsay, S.-C., and Stamnes, K. H.: MODTRAN4: Multiple Scattering and Bi-Directional Reflectance Distribution Function (BRDF) Upgrades to MODTRAN, SPIE Proceeding on Optical Spectroscopic Techniques and Instrumentation for Atmospheric and Space Research III, 3756, 354-362, 1999.

Bassford, M. R., McLinden, C. A., and Strong, K.: Zenith-sky measurements of stratospheric gases: The sensitivity of air mass factors to geophysical parameters and the influence of tropospheric clouds, J. Quant. Spec. Rad. Trans., 68, 657-677, 2001.

Berk, A., Anderson, G. P., Bernstein, L. S., Acharya, P. K., Dothe, H., Matthew, M. W., Adler-Golden, S. M., Chetwynd, J. H. J., Richtsmeier, S. C., Pukall, B., Allred, C. L., Jeong, L. S., and Hoke, M. L. A.: MODTRAN4 Radiative Transfer Modeling for Atmospheric Correction, SPIE Proceeding on Optical Spectroscopic Techniques and Instrumentation for Atmospheric and Space Research III, 3756, 348-353, 1999.

Berk, A., Anderson, G. P., Acharya, P. K., Hoke, M. L., Chetwynd, J. H., Bernstein, L. S., Shettle, E. P., Matthew, M. W., and AdlerGolden, S. M.: MODTRAN4 Version 3 Revision 1 User's Manual. Air Force Research Laboratory, Space Vehicles Directoriate, Air Force Materiel Command, Hanscom AFB, MA 01731-3010, Hanscom, 2003.

Bobrowski, N., Hönninger, G., Galle, B., and Platt, U.: Detection of bromine monoxide in a volcanic plume, Nature, 423, 273-276, 2003.

Bogumil, K., Orphal, J., Homann, T., Voigt, S., Spietz, P., Fleischmann, O. C., Vogel, A., Hartmann, M., Bovensmann, H., Frerik, J., and Burrows, J. P.: Measurements of Molecular Absorption Spectra with the SCIAMACHY Pre-Flight Model: Instrument Characterization and Reference Data for Atmospheric Remote-Sensing in the 230-2380 nm Region, J. Photochem. Photobiol. A., 157, 167-184, 2003.

Bovensmann, H., Burrows, J. P., Buchwitz, M., Frerik, J., Noël, S., Rozanov, V. V., Chance, K. V., and Goede, A.: SCIAMACHY mission objectives and measurement modes, J. Atmos. Sci., 56, 127-150, 1999.

Bruns, M., Bühler, S., Burrows, J. P., Heue, K.-P., Platt, U., Pundt, I., Richter, A., Rozanov, A., Wagner, T., and Wang, P.: Retrieval of Profile Information from Airborne Multi Axis UV/visible Skylight Absorption Measurements, Appl. Opt., 43(22), 4415-4426, 2004.

Bruns, M., Buehler, S. A., Burrows, J. P., Richter, A., Rozanov, A., Wang, P., Heue, K.-P., Platt, U., Pundt, I., and Wagner, T.: NO2 Profile Retrieval using airborne multi axis UV-visible skylight absorption measurements over central Europe, Atmos. Chem. Phys., 6, 3049-3058, 2006, http://www.atmos-chem-phys.net/6/3049/2006/.

Burrows, J. P., Weber, M., Buchwitz, M., Rozanov, V., LadstätterWeißenmayer, A., Richter, A., DeBeek, R., Hoogen, R., Bramstedt, K., Eichmann, K. -U., Eisinger, M., and Perner, D.: The Global Ozone Monitoring Experiment (GOME): Mission Concept and First Scientific Results, J. Atmos. Sci., 56, 151-175, 1999.

Collins, D. G., Blattner, W. G., Wells, M. B., et al.: Backward Monte Carlo calculations of the polarization characteristics of the radiation emerging from spherical-shell atmospheres, Appl. Opt., 11, 2684-2696, 1972. 
Currant, R. and Hilbert, D.: Methods of Mathematical Physics, vol. 2, Interscience, New York, 1962.

Deutschmann, T. and Wagner, T.: TRACY-II Users manual, University of Heidelberg, 2006.

ESA Publication Division (SP-1182), GOME, Global Ozone Monitoring Experiment, users manual, edited by: Bednarz, F., European Space Research and Technology Centre (ESTEC), Frascati, Italy, 1995.

EUMETSAT: GOME-2 Products Guide, http://www.eumetsat.int/ en/area4/eps/product_guides/GOME-2/GOME2-PG.pdf, 2005.

Frieß, U., Monks, P. S., Remedios, J. J., Rozanov, A., Sinreich, R., Wagner, T., and Platt, U.: MAX-DOAS O4 measurements: A new technique to derive information on atmospheric aerosols: 2. Modeling studies, J. Geophys. Res., 111, D14203, doi:10.1029/2005JD006618, 2006.

Frins, E., Bobrowski, N., Platt, U., and Wagner, T.: Tomographic MAX-DOAS observations of sun-illuminated targets: a new technique providing well-defined absorption paths in the boundary layer, Appl. Opt., 45, 6227-6240, 2006.

Greenblatt, G. D., Orlando, J. J., Burkholder, J. B., and Ravishankara, A. R.: Absorption measurements of oxygen between 330 and 1140 nm, J. Geophys. Res., 95, 18 577-18 582, 1990.

Heckel, A., Richter, A., Tarsu, T., Wittrock, F., Hak, C., Pundt, I., Junkermann, W., and Burrows, J. P.: MAX-DOAS measurements of formaldehyde in the Po-Valley, Atmos. Chem. Phys., 5, 909918, 2005 http://www.atmos-chem-phys.net/5/909/2005/.

Hendrick, F., Van Roozendael, M., Kylling, A., Petritoli, A., Rozanov, A., Sanghavi, S., Schofield, R., von Friedeburg, C., Wagner, T., Wittrock, F., Fonteyn, D., and De Mazière, M.: Intercomparison exercise between different radiative transfer models used for the interpretation of ground-based zenith-sky and multiaxis DOAS observations, Atmos. Chem. Phys., 6, 93-108, 2006, http://www.atmos-chem-phys.net/6/93/2006/.

Hönninger G. and Platt, U.: The Role of BrO and its Vertical Distribution during Surface Ozone Depletion at Alert, Atmos. Environ., 36, 2481-2489, 2002.

Hönninger, G., von Friedeburg, C., and Platt, U.: Multi Axis Differential Optical Absorption Spectroscopy (MAX-DOAS), Atmos. Chem. Phys., 4, 231-254, 2004, http://www.atmos-chem-phys.net/4/231/2004/.

Iwabuchi, H.: Efficient Monte Carlo methods for radiative transfer modeling, J. Atmos. Sci., 63, 2324-2339, 2006.

Leser, H., Hönninger, G., and Platt, U.: MAX-DOAS measurements of $\mathrm{BrO}$ and $\mathrm{NO} 2$ in the marine boundary layer, Geophys. Res. Lett., 30, 10, doi:10.1029/2002GL015811, 2003.

Levelt, P. F. and Noordhoek, R.: OMI Algorithm Theoretical Basis Document Volume I: OMI Instrument, Level 0-1b Processor, Calibration \& Operations, Tech. Rep. ATBD-OMI-01, Version 1.1, August 2002.

Loughman, R. P., Griffioen, E., Oikarinen, L., Postylyakov, O. V., Rozanov, A., Flittner, D. E., and Rault, D. F.: Comparison of radiative transfer models for limb-viewing scattered sunlight measurements, J. Geophys. Res., 109(D6), D06303, doi:10.1029/2003JD003854, 2004.

Marchuk, G., Mikhailov, G., Nazaraliev, M., Darbinjan, R., Kargin, B., and Elepov, B.: The Monte Carlo Methods in Atmospheric Optics, Springer-Verlag Berlin, 208 pp, 1980.

Mayer, B. and Kylling, A.: Technical note: The libRadtran software package for radiative transfer calculations - description and examples of use, Atmos. Chem. Phys., 5, 1855-1877, 2005, http://www.atmos-chem-phys.net/5/1855/2005/.

McLinden, C. A., McConnell, J. C., Griffioen, E., and McElroy, C. T.: A vector radiative transfer model for the Odin/OSIRIS project, Can. J. Phys., 80, 375-393, 2002.

McLinden, C. A., Olsen, S., Hannegan, B., Wild, O., Prather, M. J., and Sundet, J.: Stratospheric ozone in 3-D models: A simple chemistry and the cross-tropopause flux, J. Geophys. Res., 105, 14 653-14 665, 2000.

McLinden, C. A., Haley, C. S., and Sioris, C. E.: Diurnal effects in limb scatter observations, J. Geophys. Res., 111, D14302, doi:10.1029/2005JD006628, 2006.

Noxon, J. F., Whipple, E. C., and Hyde, R. S.: Stratospheric $\mathrm{NO}_{2} .1$. Observational method and behaviour at midlatitudes, J. Geophys. Res, 84, 5047-5076, 1979.

Oetjen, H., Wittrock, F., Brinksma, E., Fietkau, S., Hak, C., Heckel, A., Junkermann, W., Medeke, T., Richter, A., and Burrows, J. P.: BREDOM: Using MAX-DOAS Measurements for long-term Observations of tropospheric Trace Gases, in: proceedings of the ACCENT AT2 symposium, Urbino, September 2005.

Palazzi, E., Petritoli, A., Giovanelli, G., Kostadinov, I., Bortoli, D., Ravegnani, F., and Sackey, S. S.: PROMSAR: A backward Monte Carlo spherical RTM for the analysis of DOAS remote sensing measurements, Adv. Space Res., 36(5), 10071014, 2005.

Perliski, L.M. and Solomon, S.: On the evaluation of air mass factors for atmospheric near-ultraviolet and visible absorption spectroscopy, J. Geophys. Res., 98, 10363-10374, 1993.

Postylyakov, O. V.: Linearized vector radiative transfer model $\mathrm{MCC}++$ for a spherical atmosphere, J. Quant. Spectrosc. Radiat. Trans., 88(1-3), 297-317, doi:10.1016/j.jqsrt.2004.01.009, 2004.

Postylyakov, O. V.: Spherical radiative transfer model with computation of layer air mass factors, and some of its applications, Izvestiya, Atmos. Oceanic Phys., 40(3), 276-290, 2004.

Postylyakov, O. V.: Radiative transfer model MCC++ with evaluation of weighting functions in spherical atmosphere for use in retrieval algorithms, Adv. Space Res., 34(4), 721-726, doi:10.1016/j.asr.2003.07.070, 2004, 2003.

Postylyakov, O. V., Belikov, Yu. E., Nikolaishvili, Sh. S., and Rozanov, A.: A comparison of radiation transfer algorithms for modelling of the zenith sky radiance observations used for determination of stratospheric trace gases and aerosol, in: IRS 2000: Current Problems in Atmospheric Radiation, edited by: Smith, W. L. and Timofeyev, Yu. M., A. Deepak Publishing, Hampton, Virginia, 885-888, 2001.

Rodgers, C. D.: Retrieval of atmospheric temperature and composition from remote measurements of thermal radiation, Rev. Geophys. Space Phys., 14, 609-624, 1976.

Rodgers, C. D.: Inverse Methods for Atmospheric Sounding, World Scientific, London, 2000.

Rozanov, A. V., Rozanov, V. V., and Burrows, J.-P.: Combined differential-integral approach for the radiation field computation in a spherical shell atmosphere: Nonlimb geometry, J. Geophys. Res., 105(D18), 22 937-22 942, doi:10.1029/2000JD900378, 2000.

Rozanov, A., Rozanov, V.-V., and Burrows J.-P.: A numerical radiative transfer model for a spherical planetary atmosphere: com- 
bined differential-integral approach involving the Picard iterative approximation, J. Quant. Spectr. Radiat. Trans., 69(4), 491-512, 2001.

Rozanov, A., Rozanov, V.-V, Buchwitz, M., Kokhanovsky, A., and Burrows, J. P.: SCIATRAN 2.0. A new radiative transfer model for geophysical applications in the $175-2400 \mathrm{~nm}$ spectral region, Adv. Space Res., 36(5), 1015-1019, 2005.

Rozanov, A.: SCIATRAN 2.X: Radiative transfer model and retrieval software package, http://www.iup.physik.uni-bremen.de/ sciatran, 2004-2006.

Sarkissian, A., Roscoe, H. K., Fish, D., Van Roozendael, M., Gil, M., Chen, H. B., Wang, P., Pommereau, J.-P., and Lenoble, J.: Ozone and NO2 air-mass factors for zenith-sky spectrometers: Intercomparison of calculations with different radiative transfer models, Geophys. Res. Lett., 22(9), 1113-1116, 1995.

Sinreich, R., Frieß, U., Wagner, T., and Platt, U.: Multi axis differential optical absorption spectroscopy (MAX-DOAS) of gas and aerosol distributions, Faraday Discuss., 130, 153-164, doi:10.1039/b419274p, 2005.

Solomon, S., Schmeltekopf, A. L., and Sanders, R. W.: On the interpretation of zenith sky absorption measurements, J. Geophys. Res, 92, 8311-8319, 1987.

United States Committee on Extension to the Standard Atmosphere: U.S. Standard Atmosphere, 1976, National Oceanic and Atmospheric Administration, National Aeronautics and Space Administration, United States Air Force, Washington D.C., 1976.

Van Roozendael, M., Fayt, C., Post, P., Hermans, C., and Lambert, J.-C.: Retrieval of $\mathrm{BrO}$ and $\mathrm{NO}_{2}$ from UV-Visible Observations, in: Sounding the troposphere from space: a new era for atmospheric chemistry, Springer-Verlag, ISBN 3-540-40873-8, edited by: Borell, P., Borrell, P. M., Burrows, J. P., and Platt, U., 2003.
Von Friedeburg, C.: Derivation of Trace Gas Information combining Differential Optical Absorption Spectroscopy with Radiative Transfer Modelling, PhD-thesis, University of Heidelberg, 2003.

Von Friedeburg, C., Pundt, I., Mettendorf, K.-U., Wagner, T., and Platt, U.: Multi-AXis-(MAX) DOAS Measurements of $\mathrm{NO}_{2}$ during the BAB II Motorway Emission Campaign, J. Atmos. Environ., 39(5), 977-985, 2005.

Wagner, T., von Friedeburg, C., Wenig, M., Otten, C., and Platt, U.: UV/vis observations of atmospheric $\mathrm{O}_{4}$ absorptions using direct moon light and zenith scattered sunlight under clear and cloudy sky conditions, J. Geophys. Res., 107(D20), 4424, doi:10.1029/2001JD001026, 2002.

Wagner, T., Dix, B., von Friedeburg, C., Frieß, U., Sanghavi, S., Sinreich, R., and Platt, U.: MAX-DOAS O4 measurements: A new technique to derive information on atmospheric aerosols - principles and information content, J. Geophys. Res., 109, doi:10.1029/2004JD004904, 2004.

Wagner, T., Beirle, S., Grzegorski, M., Sanghavi, S., and Platt, U.: El-Niño induced anomalies in global data sets of water vapour and cloud cover derived from GOME on ERS-2, J. Geophys. Res, 110, D15104, doi:10.1029/2005JD005972, 2005.

Wittrock, F., Oetjen, H., Richter, A., Fietkau, S., Medeke, T., Rozanov, A., and Burrows, J. P.: MAX-DOAS measurements of atmospheric trace gases in Ny-Ålesund - Radiative transfer studies and their application, Atmos. Chem. Phys., 4, 955-966, 2004, http://www.atmos-chem-phys.net/4/955/2004/.

Wittrock, F.: The retrieval of oxygenated volatile organic compounds by remote sensing techniques, Dissertation, Institute of Environmental Physics, University of Bremen, Bremen, 2006. 